\title{
Galectins in the tumor microenvironment: Focus on galectin-1
}

Neus Martínez-Bosch ${ }^{1}$ and Pilar Navarro ${ }^{1,2}$

${ }^{1}$ Cancer Research Program, Hospital del Mar Medical Research Institute (IMIM), Unidad Asociada IIBB-CSIC, Doctor Aiguader 88; 08005-Barcelona, Spain

${ }^{2}$ Institute of Biomedical Research of Barcelona (IIBB-CSIC), Rosselló 161, 08036-Barcelona, Spain

\section{Abstract}

In the last decades, the focus of cancer research has moved from epithelial cells to the tumor milieu, in an effort to better understand tumor development and progression, and with the important end goal of translating this knowledge into effective therapies. The galectin family of glycan-binding proteins displays important functions in cancer development and progression. Numerous groups have made outstanding contributions to deepen our knowledge about the role of galectins in the tumor-stroma crosstalk, defining them as key players in modulating interactions between tumor cells and the extracellular matrix, fibroblasts, endothelium, and the immune system. While several members of the family have been of particular interest until now, others are still considered as future exploding stars. This chapter provides an overview for galectin-1, the first identified and still one of the most well-studied galectins, and highlights the very important implications in its regulation of the tumor microenvironment in many different tumor types. Besides, a glimpse of the role of other galectins in the tumor milieu is also provided. Gaining a deeper understanding about the numerous roles of galectin-1 will not only help us to better understand other galectins but also is likely to result in the development of more effective cancer therapies.

Keywords: Galectins, galectin-1, fibroblast activation, tumor microenviroment, angiogenesis, immune evasion, tumor-stroma crosstalk, cancer therapy 


\section{Galectins: a diverse family with important biological functions}

Galectins were first referred as S-type lectins (thiol-dependent) by Drickamer et al. in 1988, to differentiate them from C-type lectins, which depended on $\mathrm{Ca}^{2+}$. This classification proved to be inaccurate, as some members do not depend on reduced cysteine residues for carbohydrate binding (Whitney et al. 1986; Frigeri et al. 1990; Hirabayashi and Kasai 1991). These proteins were also called S-Lac lectins (solublelactose binding) (Leffler et al. 1989) and it was not until 1994 when the "galectin" name was given, in order to cluster all the identified $\beta$-galactoside-binding lectins and to homogenize the nomenclature of individual members (Barondes et al. 1994). The galectin family clusters a group of proteins that have a well-conserved carbohydrate recognition domain (CRD) and are classically described to bind lactosamine-containing structures found in glycoconjugates (Cummings et al. 2015). Today, galectins comprise 15 different proteins in mammals, 11 of which are found in humans (Figure 1). Members are classified in three different groups according to their structural hallmarks: 1) proto-type galectins (galectin-1 [Gal-1], Gal-2, Gal-5, Gal-7, Gal-10, Gal11, Gal-13, Gal-14, and Gal-15), which have one CRD that can dimerize; 2) tandemrepeat galectins (Gal-4, Gal-6, Gal-8, Gal-9, and Gal-12), which contain two CRDs linked by a short peptide; and 3) a chimeric-type galectin (Gal-3), which has a large aminoterminus involved in oligomerization (Hirabayashi and Kasai 1993; Rabinovich and Conejo-García 2016) (Figure 1). Although they share general binding traits, galectins have a fine-tuned regulation at different levels, including at the redox environmental state, their subcellular localization, and their quaternary structure, all of which define ligand selectivity and interaction strengths. 
Galectins are in both the cytoplasm and nuclei and can also be secreted outside the cell by a non-conventional mechanism (Hughes 1999), being deposited into the extracellular matrix (ECM) or bound to the cell membrane (Rabinovich et al. 2007; Haudek et al. 2010). They are expressed in numerous human tissues, including the placenta, intestine, lung, spleen, and heart (Johannes et al. 2018), and by many cell types, such as epithelial, endothelial, neuronal, and immune cells (Thiemann and Baum 2016).

The first hints that galectins play a role in cancer were observed in a tumor cell line (Teichberg et al. 1975), and data from the 1980s highlighted the importance of the family in mediating tumor-stroma crosstalk. Importantly, Raz and Lotan already speculated on the possible role of a galactoside-specific lectin on the surface of tumor cells in mediating metastasis through interaction of tumor cells with endothelial or immune system cells (Raz and Lotan 1981). These data were soon validated in several experimental models, and these lectins (which were still not called galectins at that moment) emerged as key players in mediating interactions between tumor cells and the host endothelial cells, immune cells, and ECM (Raz and Lotan 1987). Since then, extensive data have highlighted the importance of the galectin family in the tumor microenvironment, controlling key events in cancer development and progression such as fibroblast activation, angiogenesis, and the immune response (Sundblad et al. 2013).

Although other members of the galectin family have shown important responses in the regulation of the tumor microenvironment (and will be briefly addressed in section VII), this review will focus on Gal-1, as this protein stands out as one of the members 
with best characterized functions in stroma activation, angiogenesis, and tumor immune evasion responses.

Gal-1 was the first member of the family to be identified and consists of a $14.5 \mathrm{KDa}$ protein of 135 amino acids that is encoded by the LSGALS1 gene located on chromosome 22q12 (Camby et al. 2006). Depending on the redox conditions, Gal-1 can be found as a monomer (oxidative conditions) or as a homodimer (reducing conditions), the subunits of which are held together by an hydrophobic core (LopezLucendo et al. 2004). The CRD in this galectin recognizes N-acetyl-lactosamine (LacNAc) residues on glycans from cell surface receptors and extracellular proteins, such as integrins, CD43, CD45, fibronectin, mucin, and laminin, but Gal-1 is also able to interact with proteins independently of their sugar-binding moieties (Camby et al. 2006). Importantly, dimeric Gal-1 can establish cell surface microdomains or lattices with multiple glycoproteins found on cell membranes. These lattices are key to organizing membrane domains, mediating signaling at the cell surface, and determining receptor stabilization by controlling endocytosis (Garner and Baum 2008). For example, dimeric Gal-1 is able to control homotypic tumor cell adhesion by interacting with integrin receptors, or cell migration and invasion by recognizing glycans on ECM proteins, such as laminin or fibronectin (Hughes 2001).

\section{Glycosylation and Gal-1 in the tumor microenvironment}

Of the protein posttranslational modifications, glycosylation gives structural identity to the molecules by coating the cell membrane (which is known as the glycocalix). Importantly, this modification determines the cell's communication with its microenvironment, including with the ECM and other distinct cell types. Glycosylation 
is a finely regulated process which is able to sense and quickly react to physiological and pathological contexts (Varki et al. 2015). Aberrant tumor glycosylation has been widely reported, and its implications for driving cancer development and progression have been partially deciphered, opening the gate to interesting applications in oncology (Pinho and Reis 2015). Some of the best known specific glycan traits in cancer include a general increase in sialic acid terminal residues, enhanced $\mathrm{N}$-glycan branching, and overexpression or de novo synthesis of sialyl Lewis antigens and short O-GalNac glycans (Varki et al. 2015).

Importantly, galectins can be secreted from cells and thus stand out as important code-readers of these altered glycosylation patterns found in cancer cell membranes or even in the ECM. For instance, Gal-1 recognizes aberrant glycans on mucin-1 expressed on the surface of cancer cells (Jeschke et al. 2006), and it can also interact with poly-N-acetyllactosamines (poly-LacNAc) on ECM proteins, such as laminin or fibronectin, to regulate cell adhesion and migration (van den Brûle et al. 1995; van den Brûle et al. 2003). Furthermore, Gal-1 also communicates with different cells within the tumor microenvironment. For instance, Gal-1 recognizes glycosylated receptors on endothelial cells (ECs) such as neuropilin-1 (NRP-1) or vascular endothelial growth factor receptor 2 (VEGFR2), triggering cell signaling pathways that induce their proliferation, migration, and activation (Hsieh et al. 2008; Croci et al. 2014). Lately, a lot of the interest in Gal-1 as a potential target in cancer therapy has focused on the ability of Gal-1 to recognize receptors in the immune compartment (such as CD43, CD45, and CD7), which leads to specific T-helper type 1 (Th1) and T-cytotoxic cell apoptosis (Perillo et al. 1995; Pace et al. 1999; Hernandez et al. 2006) as well as other 
immune evasion mechanisms (Martinez-Bosch et al. 2018b). These and other examples will be specifically addressed in the following sections.

\section{Gal-1 expression in the tumor stroma}

Gal-1 overexpression has been widely reported to be present in cancer, where in addition to being secreted by tumor cell types and deposited in the ECM, it has also been found to be expressed by diverse stromal components, including fibroblasts, ECs, neutrophils, macrophages, dendritic cells (DCs), and T-lymphocytes (Thijssen et al. 2015). In particular, Gal-1 has been reported in the stroma of prostate cancer, where it was identified as an independent predictor of recurrence(van den Brûle et al. 2001). Gal-1 has also been found overexpressed in the stroma in cervical cancer, where its levels positively correlate with pathological grade (Kohrenhagen et al. 2006). Gal-1 was also detected in the stroma of laryngeal carcinoma (Saussez et al. 2009) and epithelial ovarian cancer (van den Brûle et al. 2003), where peritumoral Gal-1 intensity positively correlates with poor progression-free survival (Kim et al. 2012) and low overall survival (Schulz et al. 2017). In breast cancer, Gal-1 levels in the stroma positively correlated with TNM stage and metastasis. Gal-1 was also expressed in the stroma of colon cancer tissue, at increasing levels as the tumor progressed (Sanjuan et al. 1997). In hepatocellular carcinoma (HCC) samples, Gal-1 also accumulated in the stroma and positively correlated with tumor size, TNM stage, vascular invasion, poor differentiation, metastasis, high rates of tumor recurrence, and low overall survival, identifying Gal-1 as an independent marker of poor prognosis in HCC (Spano et al. 2010; Wu et al. 2012; You et al. 2016). In pancreatic ductal adenocarcinoma (PDA), Gal-1 is highly overexpressed in tumors (localized in the abundant desmoplastic 
reaction) (Berberat et al. 2001; Shen et al. 2004; Pan et al. 2009; Tang et al. 2012; Chen et al. 2012; Martinez-Bosch et al. 2018a), has an increased expression in advanced precursor lesions (Pan et al. 2009) and in poorly differentiated tumors (Berberat et al. 2001), and negatively correlates with longer survival times (Chen et al. 2012). Gal-1 is also expressed in the bone marrow microenvironment of multiple myeloma patients (Abroun et al. 2008). In Hodgkin and non-Hodgkin lymphomas, Gal-1 is present in the vascular walls of lymphomas but absent from normal tissue, and it correlates with vascular density (Renatus et al. 1997; D’Haene et al. 2005). In head and neck squamous cell carcinoma (HNSCC), Gal-1 is expressed in the stroma of tumor samples but absent from normal epithelium, and it correlates with the presence of alpha smooth muscle actin ( $\alpha$-SMA)-positive cancer-associated fibroblasts (CAFs) as well as with increased levels of several known HNSCC poor-prognosis factors (Valach et al. 2012). Multiple immunohistochemical studies with large patient cohorts have described Gal-1 expression in the stroma of gastric tumors. Interestingly, its expression positively correlates with tumor size (Chen et al. 2014), tumor location (Bektas et al. 2010), differentiation grade (Bektas et al. 2010; Chen et al. 2014), TNM stage (Bektas et al. 2010; Chen et al. 2014; Zheng et al. 2016; Chong et al. 2016b), histological grade (Zheng et al. 2016), invasion depth (Zheng et al. 2016; Chong et al. 2016b), lymph node metastasis (Bektas et al. 2010; Zheng et al. 2016; Chong et al. 2016b), lymphovascular invasion (Bektas et al. 2010), perineural and serosal invasion (Bektas et al. 2010), lower patient survival (Bektas et al. 2010; Chen et al. 2014; Zheng et al. 2016; Chong et al. 2016b), and with the expression of several markers, including vascular endothelial growth factor (VEGF) (Chen et al. 2014), Gli-1 (Chong et al. 2016b), vimentin, E- 
al. 2016) (Table 1).

\begin{tabular}{|c|c|c|c|}
\hline Tissue & Sample & Functions & Ref \\
\hline \multirow[t]{2}{*}{ Prostate } & 148 patients & Predictor of recurrence & $\begin{array}{l}\text { van den Brûle et al. } \\
2001\end{array}$ \\
\hline & 100 patients & Increased expression in EC from capillaries infiltrating the tumor & Clausse et al. 1999 \\
\hline Cervical & $\begin{array}{l}20 \text { benign } \\
\text { cervical tissue, } \\
40 \\
\text { intraepithelial } \\
\text { lesions, and } 20 \\
\text { invasive SCC }\end{array}$ & Increased expression according to pathologic grade & $\begin{array}{l}\text { Kohrenhagen et al. } \\
2006\end{array}$ \\
\hline \multirow[t]{3}{*}{ Ovarian } & 66 tumors & Negative correlation with progression free survival & Kim et al. 2012 \\
\hline & 156 tumors & Overall survival & Shulz et al. 2017 \\
\hline & 30 tumors & Increased expression compared with normal stroma & $\begin{array}{l}\text { van den Brûle et al. } \\
2003\end{array}$ \\
\hline \multirow[t]{5}{*}{ Gastric } & 108 tumors & $\begin{array}{l}\text { Positive correlation with tumor size, differentiation grade, TNM } \\
\text { stage, lymph node metastasis and VEGF expression }\end{array}$ & Chen et al. 2014 \\
\hline & $\begin{array}{l}111 \text { tumors and } \\
\text { adjacent } \\
\text { normal tissue }\end{array}$ & $\begin{array}{l}\text { Positive correlation with tumor invasion, lymph node metastasis, } \\
\text { TNM stage and poor prognosis }\end{array}$ & Chong et al. 2016 \\
\hline & 93 tumors & $\begin{array}{l}\text { Positive correlation with tumor location, lymphovascular, perineural } \\
\text { and serosal invasions, differentiation, stage and lymph node } \\
\text { metastasis, and poor patient survival }\end{array}$ & Bektas et al. 2010 \\
\hline & 134 tumors & $\begin{array}{l}\text { Positive correlation with histological grade, invasion depth, lymph } \\
\text { node metastasis, TNM stage and TGF } \beta \text { staining }\end{array}$ & Zheng et al. 2016 \\
\hline & $\begin{array}{l}162 \text { paired } \\
\text { gastric cancer } \\
\text { tissues and } \\
\text { noncancerous } \\
\text { tissues }\end{array}$ & $\begin{array}{l}\text { Negatively associated with E-cadherin expression but positively } \\
\text { correlated with vimentin expression }\end{array}$ & Chong et al. 2016 \\
\hline \multirow[t]{2}{*}{ Breast } & 105 tumors & $\begin{array}{l}\text { Positive correlation with invasion, T stage, TNM stage, lymph node } \\
\text { metastasis }\end{array}$ & Jung et al. 2007 \\
\hline & 55 tumors & $\begin{array}{l}\text { Positive correlations between Gal-1 positive cells and Scarff-Bloom- } \\
\text { Richardson scale (histological grades } 2 \text { and } 3 \text { ) }\end{array}$ & $\begin{array}{l}\text { Dalotto-Moreno et } \\
\text { al. } 2013\end{array}$ \\
\hline Colon & $\begin{array}{lr}25 \text { samples } & \text { of } \\
\text { mucosae, } & 15 \\
\text { adenomas, } & 25 \\
\text { carcinomas, } & \\
\text { and } & 11 \\
\text { metastases } & \\
\end{array}$ & $\begin{array}{l}\text { Increased expression with tumor progression from normal mucosae } \\
\text { to adenomas and carcinomas }\end{array}$ & Sanjuan et al. 1997 \\
\hline \multirow[t]{3}{*}{ HCC } & $386 \mathrm{HCC}$ & $\begin{array}{l}\text { Positive association with tumor invasive characteristics, and poor } \\
\text { tumor recurrence and overall survival }\end{array}$ & Wu et al. 2012 \\
\hline & $197 \mathrm{HCC}$ & Positive correlation with metastasis & Spano et al. 2010 \\
\hline & $\begin{array}{l}162 \mathrm{HCC} \text { and } 12 \\
\text { normal liver } \\
\text { samples }\end{array}$ & $\begin{array}{l}\text { Positive correlation with tumor size, differentiation, TNM stage and } \\
\text { distant metastasis. Negatively with CD3 }\end{array}$ & You et al. 2016 \\
\hline $\begin{array}{l}\text { Laryngeal } \\
\text { carcinoma }\end{array}$ & $\begin{array}{l}53 \quad \text { LSCC of } \\
\text { different stages } \\
(\mathrm{I}, \mathrm{II}, \mathrm{IV})\end{array}$ & $\begin{array}{l}\text { Positive correlation with EC, negative correlation with CD45. } \\
\text { Increased expression in the tumor stroma compared to normal } \\
\text { stroma }\end{array}$ & Saussez et al. 2009 \\
\hline \multirow[t]{5}{*}{ PDA } & $\begin{array}{lr}33 & \text { normal } \\
\text { pancreas, } & 21 \\
\text { adjacent } & 30 \\
\text { benign CP, } & 45 \\
\text { adjacent CP, } & 17 \\
\text { dysplasias, and } \\
\text { 43 PDA }\end{array}$ & Negative correlation with very long-term survival and longer survival & Chen et al. 2012 \\
\hline & $\begin{array}{l}66 \text { PDA, } 18 \mathrm{CP} \text {, } \\
\text { 10NP }\end{array}$ & Expression: Normal<CP<PDA & Tang et al. 2012 \\
\hline & $\begin{array}{l}19 \mathrm{NP}, 13 \mathrm{CP}, 9 \\
\text { PanIN, } 7 \text { IPMN, } \\
\text { and } 30 \text { PDA }\end{array}$ & Expression: Normal<CP PDA & $\begin{array}{l}\text { Martinez-Bosch et } \\
\text { al. 2018a }\end{array}$ \\
\hline & $\begin{array}{l}28 \text { NP and } 33 \\
\text { PDA }\end{array}$ & $\begin{array}{l}\text { Overexpression in tumors compared to normal pancreas. Increased } \\
\text { Gal-1 in poorly differentiated versus well-differentiated tumors }\end{array}$ & Berberat et al. 2001 \\
\hline & $33 \mathrm{NP}, 17$ PanIN & Increased expression in advanced PanIN and PDA & Pan et al. 2009 \\
\hline
\end{tabular}




\begin{tabular}{|l|l|l|l|}
\hline & and 43 PDA & & \\
\hline & $\begin{array}{l}\text { G NP, 7 CP, 6 } \\
\text { PDA }\end{array}$ & $\begin{array}{l}\text { Overexpressed in tumors compared to normal and pancreatitis } \\
\text { tissue }\end{array}$ & Shen Jet et al. 2004 \\
\hline Myeloma & $\begin{array}{l}\text { 30MM (multiple } \\
\text { myeloma) }\end{array}$ & Gal-1 in the extracellular space & $\begin{array}{l}\text { Abroun S et al. } \\
2008\end{array}$ \\
\hline $\begin{array}{l}\text { (non) } \\
\text { Hodgkin } \\
\text { lymphoma }\end{array}$ & $\begin{array}{l}25 \text { normal lymp } \\
\text { hoid tissues, 42 } \\
\text { non-Hodgkins } \\
\text { and } \\
\text { Hodgkins lymph } \\
\text { omas }\end{array}$ & Gal-1 in blood vessels & D'Haene N et al. \\
& $\begin{array}{l}31 \text { patients with } \\
\text { HNSCC and } \\
\text { adjacent } \\
\text { normal } \\
\text { epithelium }\end{array}$ & $\begin{array}{l}\text { Gal-1 overexpressed in the tumor stroma, correlating with } \alpha \text {-SMA+ } \\
\text { fibroblasts }\end{array}$ & Valach et al. 2012 \\
\hline HNSCC & & & \\
\hline
\end{tabular}

\section{Gal-1 and fibroblast activation}

Several reports have addressed how Gal-1 regulates physiological fibroblast function.

Gal-1 induces rodent myofibroblast differentiation, activation (Goldring et al. 2002), proliferation, and migration (Maeda et al. 2003), and Gal-1 knockout (KO) mice show impaired wound healing responses (Lin et al. 2015). Mechanistically, Gal-1 promotes myofibroblast activation by triggering intracellular reactive oxygen species (ROS) production by regulating the NADPH oxidase 4 (NOX4) via the NRP-1/Smad3 signaling pathway in myofibroblasts (Lin et al. 2015). In vitro, TGF- $\beta 1$ activates fibroblasts by increasing Gal-1 expression through phosphoinositide 3-kinases (PI3K) and p38 mitogen-activated protein kinase (MAPK), and by retaining phosphorylated Smad2 in the nuclei, allowing cells to differentiate (Jin Lim et al. 2014). In liver, Gal-1 promotes hepatic stellate cell migration and invasion through its binding to NRP-1, and signaling through platelet-derived growth factor (PDGF) and TGF- $\beta 1$ (Wu et al. 2017a). In experimental mouse models with liver fibrosis, Gal-1 gene silencing in hepatic stellate cells results in downregulation of connective tissue growth factor (CTGF) and $\alpha$-SMA, and thus inhibition of cell proliferation and migration and concurrent promotion of 
apoptosis (Jiang et al. 2019). Indeed, reduced collagen and $\alpha$-SMA expression were detected in liver fibrosis when studied in Gal-1 KO backgrounds (Wu et al. 2017a).

As Gal-1 is overrepresented in many tumor stroma microenvironments and its expression correlates with several clinicopathological tumor features (Table 1), it seems likely that it has an important role in this key tumor compartment. In oral squamous cell carcinoma (OSCC)-derived fibroblasts, Gal-1 downregulation decreases a-SMA and reduces ECM deposits in vitro (Wu et al. 2011) and impairs tumor progression and metastasis in vivo (Wu et al. 2011). In pancreatic cancer, the role of Gal-1 in activating CAFs (termed pancreatic stellate cells, PSCs) has been well established. In particular, our group has shown that genetic inhibition of Gal-1 in PSCs, or in different preclinical transgenic mouse models of pancreatic cancer, results in tumors with reduced $\alpha$-SMA content and impairs tumor growth and metastasis, thereby increasing animal survival (Martínez-Bosch et al. 2014; Orozco et al. 2018). In addition, we have also shown that Gal-1 modulates Hedgehog signaling in PSCS (Martínez-Bosch et al. 2014). Further, Gal-1 modulates proliferation and enhances the release of monocyte chemotactic protein 1 (MCP-1) and cytokine-induced neutrophil chemoattractant-1 (CINC-1) in PSCs, thereby activating extracellular signal-regulated kinase (ERK), c-Jun N-terminal kinase (JNK), activator protein 1 (AP-1), and the transcription factor nuclear factor kappa-light-chain-enhancer of activated B cells (NFKB) (Masamune et al. 2006). Recently, in vitro approaches have also shown that Gal-1 regulates proliferation and migration of PSCs and that the expression of Gal-1 positively correlates with increased levels of fibronectin, collagen type I, $\alpha$-SMA, matrix metalloproteinase 2 (MMP-2), and tissue inhibitor of metalloproteinases 1 (TIMP-1), through the TGF- $\beta 1 /$ Smad pathway (Tang et al. 2018). Finally, in patients with 
pancreatic cancer, Gal-1 staining in the tumor microenvironment has been proven by multivariate survival analysis to be an independent prognostic factor (Tang et al. 2014). Gal-1 role in inducing fibroblast activation has been addressed in several other tumor settings, such as in human breast cancer, in which Gal-1 knockdown reduces expression of $\alpha-S M A$, fibroblast activation protein (FAP), and fibronectin, while overexpression of Gal-1 by transfection of breast normal fibroblasts induces differentiation towards a myofibroblast phenotype (Zhu et al. 2016). In HNSCC, Gal-1 overexpression correlates with the presence of $\alpha$-SMA-positive activated CAFs in the tumor (Valach et al. 2012) (Figure 2).

In addition to its autochthonous functions in activated fibroblasts, Gal-1 has an important paracrine effect over the cancer cell compartment. For instance, in breast cancer, fibroblast-derived Gal-1 promotes cancer cell migration and invasion by induction of MMP-9 (Zhu et al. 2016), a pattern that has also been observed in human breast cancer patients (Jung et al. 2007). Fibroblast-derived Gal-1 has similar protumoral functions in gastric cancer, via integrin $\beta 1$ binding (He et al. 2014). Further, this axis is also responsible for Gli-1 upregulation in gastric cancer cells, resulting in epithelial-mesenchymal transition (EMT) (Chong et al. 2016). In ovarian cancer, Gal-1 secreted from fibroblasts modulated cancer cell invasion through MMP-2 (Kim et al. 2012). In pancreatic cancer, fibroblast-derived Gal-1 increases tumor proliferation and invasion by upregulating MMP-2 and MMP-9 in cancer cells (Xue et al. 2011; Tang et al. 2014). Besides, PSC increases the in vitro and in vivo tumorigenic capacity of pancreatic tumoral cells via paracrine secretion of Gal-1 and gene expression analysis in a pancreatic cancer cell line (RWP-1) upon addition of recombinant Gal-1 brought additional hints on the molecular mechanisms driving these effects by identifying 
genes involved in cell proliferation, migration, metastasis and cell metabolism (Orozco et al. 2018). Finally, in OSCC, Gal-1 regulates cancer cell migration through MCP-1 fibroblast secretion and binding to C-C chemokine receptor type 2 (CCR2) in tumor cells (Wu et al. 2011).

Paracrine effects of fibroblast-secreted Gal-1 are not restricted to cancer cells but also rely on signals from other cells of the tumor microenvironment. In pancreatic cancer, Gal-1 from PSCs drives tumor immune privilege by promoting T-cell apoptosis and Th2 cytokine secretion (Tang et al. 2012; Martínez-Bosch et al. 2014; Martinez-Bosch et al. 2018b; Orozco et al. 2018). In gastric cancer, Gal-1 derived from CAFs interacts with ECs to induce proliferation, migration, and tube formation, resulting in increased angiogenesis and tumor progression (Tang et al. 2016).

\section{Gal-1 in the tumor endothelium}

Gal-1 staining in the endothelium was already described in 1986 (Gabius et al. 1986), and it has been long known to be upregulated upon EC activation (Baum et al. 1995b; La et al. 2003; Thijssen et al. 2006, 2008), and in particular in cancer-associated capillaries in several tumors, such as prostate (Clausse et al. 1999), breast, Ewing sarcoma, colon (Thijssen et al. 2006, 2008), HNSCC, OSCC (Hsieh et al. 2008), and lung carcinomas (Lotan et al. 1994). Overexpression of Gal-1 in tumors can be explained by their typical hypoxic microenvironment, as Gal-1 has been reported to be upregulated upon hypoxia (Le et al. 2005; Croci et al. 2012). For example, Gal-1 is upregulated in colorectal cancer cell lines by hypoxia inducible factor 1 (HIF-1)-dependent mechanisms (Zhao et al. 2010). Alternatively, in Kaposi's sarcoma, hypoxia-mediated increases of Gal-1 expression is driven by ROS-dependent activation of NF-kB (Croci et al. 2012). 
Gal-1 modulates EC activity, inducing their proliferation, migration, and tubulogenesis in vitro (Thijssen et al. 2006, 2010; Le Mercier et al. 2008; Hsieh et al. 2008; Ito et al. 2011; Laderach et al. 2013; Tang et al. 2016; Manzi et al. 2016). Indeed, ECs derived from Gal-1 KO mice show reduced tubular networks compared with wild type mice (Mathieu et al. 2012). One of the mechanisms that has been proposed for Gal-1mediated angiogenesis is signaling through endoplasmic reticulum transmembrane kinase/ribonuclease inositol-requiring enzyme 1alpha (IRE1 $\alpha)$, resulting in regulation of oxygen-regulated protein 150 (ORP150) (Le Mercier et al. 2009), a chaperone which modulates VEGF maturation (Ozawa et al. 2001) (Figure 2).

In addition to the relevance of endogenous Gal-1 in EC biology, several reports have also highlighted the importance of exogenous Gal-1 in endothelium functions, in particular in cancer angiogenesis. Indeed, Thijssen et al. (Thijssen et al. 2010) reported that Gal-1 secreted by tumor cells can be uptaken by ECs and signal through H-Ras and the downsteam Raf/MAPK/ERK pathway to induce EC migration and proliferation (Thijssen et al. 2010) (Figure 2). Along this line, different cancer cells knocked down for Gal-1 behave similarly, irrespective of being implanted into wild-type or Gal-1 KO mice, highlighting the importance of tumor-secreted Gal-1 for angiogenesis (Mathieu et al. 2012; Croci et al. 2012, 2014). Indeed, tumor-derived Gal-1 enhances EC viability and protects them from apoptosis in the oxidative stress situations that frequently occur in the tumor microenvironment (Ito et al. 2011).

Importantly, most of the mechanisms concerning Gal-1 exerting pro-angiogenic effects in tumors have orbited around the VEGFR family of proteins. Gal-1 interaction with NRP-1, a known co-receptor for VEGF (Soker et al. 1998); results in VEGFR2 activation 
and downstream signaling stress-activated protein kinase-1/c-Jun NH2-terminal kinase (SAPK/JNK) (Figure 2), thereby inducing migration and adhesion of ECs in a model of OSCC (Hsieh et al. 2008). Importantly, Croci et al. described that Gal-1 can directly bind to VEGFR2 when displays cancer-specific glycosylation patterns, triggering its activation in the absence of VEGF, resulting in anti-VEGF-resistant tumors (Croci et al. 2014). Extracellular Gal-1 increases vascular permeability through interactions with NRP-1 and VEGFR1, triggering Akt activation and impairing vascular endothelialcadherin at cell/cell junctions (Wu et al. 2014). Further, Gal-1 and Gal-3 in combination exert an enhanced pro-angiogenic effect through VEGFR1 activation, probably linked to impaired receptor endocytosis (D'Haene et al. 2013). Gal-1 can also promote neovascularization by modulating platelet VEGF release through protein kinase C (PKC) and ERK signaling (Etulain et al. 2014). Besides the VEGF-VEGFR pathway, other molecular mechanisms have been related to activation of ECs by tumor-secreted Gal-1. For example, microarray analyses comparing glioblastoma cells knocked down for Gal1 as compared to the parental cell line reveal reduced levels of microvascular differentiation gene 1 (MDG1), a marker of EC activation (Berger et al. 2003) and other hypoxia-regulated pro-angiogenic molecules (Le Mercier et al. 2009). In the same direction, Gal-1 inhibition in multiple myeloma cell lines decreases MMP9 and chemokine (C-C motif) ligand 2 (CCL2) and increases semaphorin 3A (SEMA3A) and (CX-C motif) chemokine 10 (CXCL10) (Storti et al. 2016). Gal-1 also impairs vasculogenesis in vitro and in vivo through expression of brain-expressed X-linked gene (BEX2) in an oligodendroglioma model (Le Mercier et al. 2009).

Given the importance of neovascularization in tumor development and progression, much preclinical effort has been centered on deciphering the effects of Gal-1 
downregulation or blockade in tumors. Further, Gal-1 has been linked to metastasis through its involvement in establishing heterotypic interactions between ECs and tumor cells (Lotan et al. 1994; Lehr and Pienta 1998; Thijssen et al. 2007). Gal-1 triggers tumor angiogenesis in vivo in experimental models (Thijssen et al. 2006), and tumors grown or developed in Gal-1 KO mice show impaired angiogenesis (Thijssen et al. 2006; Martínez-Bosch et al. 2014; Büchel et al. 2016; Orozco et al. 2018). Further, Gal-1 knockdown in tumor cells inoculated into nude mice result in impaired tumor angiogenesis in Kaposi's sarcoma (Croci et al. 2012), prostate cancer (Laderach et al. 2013), kidney cancer (Huang et al. 2014), myeloma (Storti et al. 2016), melanoma, and breast cancer xenografts (Ito et al. 2011). Gal-1 downregulation in Lewis lung carcinoma or T-cell lymphoma cancer cell lines render them sensitive to anti-VEGF therapy by impairing Gal-1-driven angiogenesis (Croci et al. 2014). Likewise, Gal-1 expression positively correlates with VEGF and Gal-1 knockdown in gastric CAFimpaired tumor growth and angiogenesis in vivo (Tang et al. 2016).

Altogether, information generated by these preclinical studies has laid the foundation for the development of Gal-1 pharmacological inhibitors as a novel antiangiogenic therapeutic arsenal. Accordingly, strategies closer to clinical translation have also been assessed in preclinical setups, such as the use of Gal-1 antibodies, which in Kaposi's sarcoma result in tumor regression due to impaired angiogenesis (Croci et al. 2012), and in melanoma and Lewis lung carcinoma syngenic models restore a functional vascular network rendering tumors sensitive to anti-VEGF therapy (Croci et al. 2014). Similarly, intratumor injections of a Gal-1 antibody impairs vascular permeability and tumor growth in OSCC xenografts (Wu et al. 2014). In glioblastoma, introducing antiGal-1 siRNA into mouse brains significantly decreases angiogenesis and enhances the 
effects of temozolamide (Le Mercier et al. 2008). Anginex, an angiostatic peptide that targets Gal-1, shows impaired angiogenesis and tumor growth in a teratocarcinoma syngenic model, which of course could not be observed in a Gal-1 KO background (Thijssen et al. 2006). Very recently, synthetic glycomimetic compounds (Phostine 3.1a) targeting the VEGFR2 and Gal-1 interaction have shown effectiveness in impairing angiogenesis in vitro and in vivo in a glioblastoma model (Bousseau et al. 2019). Intratumor injections of thiodigalactoside (TDG) (a non-metabolized small drug that targets the amphipathic $\beta$-sheet of Gal-1) reduces EC content and tumor growth in melanoma and breast cancer models (Ito et al. 2011). OTX008 (a calixarene compound targeting the CRD of Gal-1) restores tumor vessel normalization and impaired tumor growth in HNSCC (Koonce et al. 2017) and ovarian xenografts (Zucchetti et al. 2013; Astorgues-Xerri et al. 2014b), where the drug potentiates cytotoxic and targeted therapies (Zucchetti et al. 2013; Astorgues-Xerri et al. 2014b). Finally, several reports using different drugs that do not directly target Gal-1 have unveiled Gal-1 to be nonetheless responsible for the pharmacological effects. For instance, in a mouse model of prostate cancer, hemin treatment decreases Gal-1 tumor levels and thus impairs angiogenesis (Jaworski et al. 2017), and anti-VEGF and anti-cytotoxic Tlymphocyte-associated protein 4 (CTLA4) combined therapy in human melanoma elicits humoral Gal-1 immune responses resulting in improved outcomes and overall survival (Wu et al. 2017b).

\section{Gal-1 in tumor immune evasion}

Many reports have highlighted the effects of Gal-1 over a wide variety of immune cell types (Rabinovich and Conejo-García 2016). In fact, the role of this protein in 
regulating the immune system homeostasis was one of the first identified functions for Gal-1 (Perillo et al. 1995). Gal-1 recognizes different glycosylated receptors in immune cells and can trigger a wide variety of cellular processes, including polarization, maturation, activation, differentiation, and apoptosis (Rabinovich and Toscano 2009; Rabinovich and Conejo-García 2016). In T-lymphocytes, Gal-1 binds to the CD43, CD45, CD7, and CD4 receptors on the cell membrane and regulates their function (Pace et al. 1999; Stillman et al. 2006).

Gal-1 plays a pleiotropic immunosuppressive role by directly targeting different immune cell types. For this reason, it has crucial physiological functions in immuneprivileged sites, such as in testis (Pérez et al. 2015), eyes (Ridano et al. 2017) and placenta, where it is key in maintaining fetomaternal tolerance in pregnancy (Blois et al. 2007). Anti-inflammatory functions of Gal-1 are found both in innate and adaptive immune responses. In fact, Gal-1 has been associated to the regulation of most of the innate immune cells. For instance, Gal-1 has been linked to inhibition of neutrophil activation and trafficking upon inflammation (Cooper et al. 2008; lqbal et al. 2011), as well as to phagocytic neutrophil removal through exposure of cell surface phosphatidylserine (Stowell et al. 2009). In macrophage polarization, Gal-1 favors an M2 profile by regulating metabolism of L-arginine, by decreased nitrogen oxide (NO) production, and/or by promoting the arginase pathway (Correa et al. 2003). Additionally, Gal-1 impairs the expression of major histocompatibility complex II (MHCII) as well as of $\mathrm{Fc} \gamma$ receptor $(\mathrm{Fc} \gamma \mathrm{R})$ on macrophages recruited to inflammation sites through ERK1/2 signaling pathway, thereby regulating the phagocytic potential (Barrionuevo et al. 2007). The pro-resolving conversion of macrophages by Gal-1 has also been linked to 12/15-lipoxygenase expression (Rostoker et al. 2013). In 
monocytes, Gal-1 induces chemotaxis and can also modulate FcyRl expression, dependent phagocytosis, and MHC-II expression and can interfere with antigen presentation (Barrionuevo et al. 2007). Gal-1 was reported to induced migration and maturation of DCs (Fulcher et al. 2006, 2009; Thiemann et al. 2015), conferring tolerogenic potential by regulating IL-2 production and inducing IL-10-mediated T-cell tolerance (Blois et al. 2007; Ilarregui et al. 2009). In the adaptive immunity, Gal-1 can modulate B-lymphocyte PI3K signaling, activation, proliferation, and differentiation (Tsai et al. 2014). However, the most important role of Gal-1 in controlling the immune system concerns T-cell function. Gal-1 can regulate T-cell effector function by inducing growth arrest and apoptosis (Baum et al. 1995a; Rabinovich et al. 1998, 2002; Blaser et al. 1998) to specifically induce Th1, Th17 and CD8+ T-cell apoptosis, highlighting an anti-inflammatory Th2 response (Rabinovich et al. 1999b, 2002; He and Baum 2004; Toscano et al. 2006, 2007; Blois et al. 2007). Further, Gal-1 is able to impair proper Tcell activation (Chung et al. 2000) and proinflammatory cytokine production (Rabinovich et al. 1999a, b; Santucci et al. 2003; Cedeno-Laurent et al. 2012c). Gal-1 also regulates T-cell differentiation (de la Fuente et al. 2014), trafficking, and transendothelial migration (Rabinovich et al. 1999a; He and Baum 2006b; Norling et al. 2008). The immunosuppressive activity of forkhead box P3 (FoxP3)-positive Tregulatory (Treg) cells is also controlled by Gal-1 (Garín et al. 2007; Baatar et al. 2009), allowing expansion of T-regulatory type-1 cells secreting interleukin 10 (IL-10) (Toscano et al. 2006; Ilarregui et al. 2009; Cedeno-Laurent et al. 2012a). Indeed, following intradermal parasite infection, Gal-1 KO mice fail to activate Gal-1-driven tolerogenic circuits and FoxP3+ regulatory T-cells, resulting in a Th1 Th17-favored profile (Poncini et al. 2015). 
Modulation of immune system response by Gal-1 together with its frequent overexpression in many tumors prompted numerous studies to explore Gal-1's role in tumor immune evasion. Importantly, in 2004, almost ten years before immunotherapy was named breakthrough of the year, Rubinstein et al. published that Gal-1 was driving tumor immune escape in melanoma, as blockade of Gal-1 in vivo induced the generation of T-cell-mediated responses, including enhanced secretion of Th1 cytokines and tumor regression (Rubinstein et al. 2004). Since then, many articles have described that Gal-1 can induce tumor immune suppression in different tumor types, trying to decipher the mechanism by interrogating both innate and adaptive tumor immune responses (Figure 2). In ovarian and lung cancer models, for instance, a major role of the lectin was reported to be to regulate DC tumor-promoting proinflammatory activities (Kuo et al. 2012; Tesone et al. 2016). In Kaposi's sarcoma, specific antibodies targeting Gal-1 in vivo showed enhanced tumor-infiltrating NK1.1 $1^{+}$natural killer (NK) cells (Croci et al. 2012). Along the same direction, in glioblastoma, Gal-1 downregulation in tumor cells impairs myeloid accumulation and tumor progression due to decreased CCL2 and VEGF expression (which are known macrophage and MDSC chemoattractants) as well as enhanced interferon gamma (IFNv) production from CD8+ T cells (Figure 2). These data were confirmed by Baker and colleagues, who have shown that Gal-1 knockdown in glioma cells leads to recruitment of Gr-1+CD11b+ myeloid cells as well as NK1.1+ NK cells in tumors, thereby impairing tumor growth (Baker et al. 2016) (Figure 2). Recent in vitro and in vivo data also have shown that Gal-1 knockdown in glioblastoma results in diminished M2 macrophages and MDSCs as well as decreased immunosuppressive cytokine production (You et al. 2016; Chen et al. 2019). In mice, intranasal delivery of siRNAs against Gal-1 also 
reduces MDSCs and Tregs, increases CD4+ and CD8+ T cells, and impairs M2 polarization in macrophages (Van Woensel et al. 2017) (Figure 2).

Most articles have described the impact of Gal-1 on the T-cell population in tumors. In pancreatic cancer, for instance, co-culturing experiments of PSCs with T-cells show that Gal-1 induces T-cell apoptosis and stimulates secretion of IL-6 and IL-10 while decreasing lymphotoxin (TNF- $\beta$ ) and IFN- $\gamma$, thus favoring a Th2 immunosuppressive profile (Tang et al. 2015) (Figure 2). These data were validated in preclinical transgenic models by our group; we reported that, in c-myc-driven pancreatic tumors, Gal-1 ablation results in tumors with increased intratumoral $\mathrm{T}$ lymphocytes and increased neutrophil populations (Martínez-Bosch et al. 2014). Similarly, in a K-Ras driven system, Gal-1 KO tumors show enhanced infiltrating T-cells and decreased MDSCs (Orozco et al. 2018). Other descriptive tissue analyses report increased T-cells due to decreased apoptosis in low Gal-1 expressing tumors of lung syngenic models(Banh et al. 2011), a link that has been also corroborated in melanoma preclinical models and in laryngeal squamous cell carcinoma patients (Saussez et al. 2009). In neuroblastoma, Gal-1 downregulation in tumor cells impairs tumor growth and metastasis due to increased accumulation of infiltrating CD4+ and CD8+ T-cells with enhanced IFN- $\gamma$ secretion, cytotoxic $\mathrm{T}$ cell function, and DC maturation, and reduced T-cell apoptosis (Soldati et al. 2012). In a model of sarcoma, myeloid-derived suppressor cells (MDSCs) were shown to promote Gal-1 secretion in $\gamma \delta$ lymphocytes in toll-like receptor 5 (TLR5) responsive tumors, resulting in immune evasion (Rutkowski et al. 2015). However, Gal1 regulation of T-cell infiltrates is not only a result of its pro-apoptotic effect. In prostate cancer for instance, Gal-1 inhibits transendothelial migration of T-cells through CD43 clustering (He and Baum 2006b), and Gal-1 inhibition with hemin 
enhances CD8+ T-cell proliferation and antigen-specific cytotoxicity in vivo (Jaworski et al. 2017). As mentioned above, Gal-1 also affects the intratumoral Treg population (Figure 2). More specifically, silencing Gal-1 in breast cancer syngenic animals reduces the presence of intratumoral and peripheral FoxP3+ Tregs, impairing its function and suppressing its activity, thus resulting in impaired tumor growth and metastasis (Dalotto-Moreno et al. 2013). Interestingly, in hematological tumors, Gal-1 has also been reported to induce immunosuppression (Cedeno-Laurent et al. 2012b, a, c) but is also relevant for the tumor cells themselves. For instance, in leukemia, Gal-1 derived from myeloid cells modulates B-cell receptor (BCR) signaling in tumor B-cells through Gal-1, thereby regulating tumor cell activity and favoring cancer progression (Croci et al. 2013). Gal-1 in neoplastic Reed-Sternberg cells in Hodgkin lymphoma impairs T-cell viability and maintains expansion of FoxP3+ Treg cells, to support an immunosuppressive Th2 milieu (Juszczynski et al. 2007; Cedeno-Laurent et al. 2012c) (Figure 2).

The relevance of tumor versus host Gal-1 in immunosuppression was addressed by regulating Gal-1 expression in cell lines and injecting them into wild-type or Gal-1 KO mouse models. Interestingly, in neuroblastoma, T-cell-derived Gal-1 regulated intratumoral infiltrates without affecting tumor growth, which was however affected by tumor-derived Gal-1 (Büchel et al. 2016); this indicates important issues that need to be considered before developing therapeutic Gal-1 targeting strategies. In lung cancer and glioblastoma, for instance, tumor Gal-1 also proved to be more determinant than host-derived Gal-1 in tumor growth and metastasis (Banh et al. 2011; Verschuere et al. 2014). Although the reasons of this difference are unknown, the authors discussed that this may be due to enhanced Gal-1 expression levels from 
tumor cells as compared to T-cells (Banh et al. 2011). Importantly, driving tumor immune evasion by Gal-1 seems to be one of the major functions of this protein in cancer, as the effects of reducing tumor growth and increasing survival observed after Gal-1 downregulation are not observed in immunodeficient mouse models (Banh et al. 2011; Croci et al. 2014; Martínez-Bosch et al. 2014).

Tumor-derived Gal-1 is not only able to promote an immunosuppressive tumor microenvironment but also to generate a systemic immunosuppression in the animal (Dalotto-Moreno et al. 2013). Indeed, in lung metastases models, inhibiting Gal-1 with TDG or reducing endogenous Gal-1 levels in tumor cell lines enhances peripheral T-cell immune responses and impairs metastases. As expected based on its important role in evading the tumor immune response, blocking Gal-1 has shown preliminary synergistic effects with immunotherapy in preclinical models. Screening The Cancer Genome Atlas (TCGA) reveals that Gal-1 levels in glioblastoma patients negatively correlates with the Th1/Treg and cytotoxic $\mathrm{T}$ lymphocytes (CTL)/Treg ratios and overall survival (Van Woensel et al. 2017). Accordingly, silencing Gal-1 improves DC vaccine and programmed cell death protein 1 (PD-1) blocking therapies in mice with glioma tumors (Verschuere et al. 2014; Van Woensel et al. 2017). Inhibitory disaccharides targeting Gal-1 also improve vaccine immunotherapy in breast cancer preclinical models (Stannard et al. 2010). In non-Hodgkin lymphoma, a forward exome screen of primary tumors identified Gal-1 as a marker of resistance to CD20 immunotherapy; this finding was validated in an in vivo preclinical model (Lykken et al. 2016).

\section{Other galectins in the tumor microenvironment}


Besides Gal-1, other galectins have garnered the attention of researchers who are trying to understand the tumor microenvironment, mainly due to their role in angiogenesis and regulation of the tumor immune response (Cerliani et al. 2017; Méndez-Huergo et al. 2017).

The role of galectins in cancer fibroblast activation appears to be monopolized by Gal1. However, Gal-3 can also be secreted (Bänfer et al. 2018; Popa et al. 2018) and is found in the stromal compartment of tumors (Logullo et al. 2007; Schulz et al. 2017). Thus, in addition to its important roles in fibroblast biology in fibrotic disease (Henderson et al. 2006; Li et al. 2014) and arthritis (Filer et al. 2009), Gal-3 also has predominant functions in CAF activation. Indeed, in 2018, Zhao and colleagues described that recombinant Gal-3 can induce proliferation, invasion, and inflammatory cytokine secretion by PSCs, which contributes to tumor growth and metastasis in preclinical mouse models (Zhao et al. 2018).

Gal-3 is also one of the best characterized members of the galectin family with respect to tumor blood vessel formation. Different reports have shown that Gal-3 induces EC morphogenesis, chemotaxis, and differentiation, leading to angiogenesis (NangiaMakker et al. 2000, 2002a, b; Markowska et al. 2010; Funasaka et al. 2014). Several mechanistic studies have tried to elucidate how Gal-3 triggers angiogenesis in tumors; these studies have shown that Gal-3 retains VEGFR2 on the membrane of ECs (Markowska et al. 2011), directly interacts with Jagged-1 (JAG1) in the EC cell membrane and activates Notch-1 (Santos et al. 2017), and induces VEGF expression from macrophages (Machado et al. 2014). Furthermore, Gal-3 regulates tumor cell 
adhesion to ECs, promoting metastasis (Nangia-Makker et al. 2002b; Shekhar et al. 2004; Funasaka et al. 2014).

Gal-8 has also been reported to play a key role in tumor angiogenesis and was classified as a pro-angiogenic molecule in 2011 by Delgado et al., who reported that this galectin controls EC migration and angiogenesis in vitro and in vivo. CD166 was identified as the receptor for Gal-8 in EC membranes (Delgado et al. 2011; Troncoso et al. 2014). Regarding Gal-9 role in tumor angiogenesis, increased levels of this lectin have been found in blood vessels from lung, liver, breast, and kidney carcinomas (Heusschen et al. 2014). Interestingly, ECs can express different splicing forms of Gal-9, and the expression of this protein is regulated during EC activation, although the precise role of Gal-9 in angiogenesis is not yet well understood (Thijssen et al. 2008). Angiogenesis induced by these different galectin members can also be triggered in an indirect way by cytokines or soluble factors. For example, both Gal-3 and Gal-8 were shown to promote VEGF release by platelets, and Gal-8 also induces endostatin secretion, leading to angiogenesis (Etulain et al. 2014). Similarly, through its function as eosinophil chemoattractant or DC expansion, Gal-9 might induce the release of proangiogenic factors by these cells (Heusschen et al. 2014).

Moving to tumor immunity regulation, other galectin family members besides Gal-1 have raised a lot of interest for cancer, being even considered as emerging immune checkpoints. Gal-3, for example, has modulatory effects on T-cell survival and activation (Fukumori et al. 2003; Stillman et al. 2006; Peng et al. 2008), NK function (Tsuboi et al. 2011; Wang et al. 2014), and DC expansion (Kouo et al. 2015). In particular, the axis of Gal-3/lymphocyte-activation gene 3 (LAG-3) has been postulated 
to be a novel cancer immune checkpoint (Melero et al. 2015). Gal-9 gained the attention of oncologists when it was identified as a partner of the T-cell exhaustion marker T-cell immunoglobulin and mucin-domain containing molecule-3 (TIM-3)(Zhu et al. 2005). Thus, the Gal-9 and TIM-3 interaction induces effector T-cell exhaustion or apoptosis, leading to tumor immune evasion; therefore, Gal-9 has been also recently added to the list of cancer immune checkpoints (Melero et al. 2015). Recent preclinical data in mouse models of liver cancer have demonstrated that therapy with antibodies against LAG-3 (i.e. targeting the Gal-3 axis) or TIM-3 (i.e. targeting the Gal-9 axis) are able to restore cancer immune surveillance and increase tumor-infiltrating T-cell number and functionality (Zhou et al. 2017). These data open new gates to assessing novel immunotherapy combinations that may result in increased percentage of responders or even allow resistance to be overcome; they further provide a rationale for studying these new immune checkpoints per se. Whether other family members have a role in promoting tumor immune suppression has not yet been elucidated, although in vitro data have already proven that Gal-2, Gal-4, and Gal-8 can also exert pro-apoptotic functions over T-cells (Tribulatti et al. 2007; Paclik et al. 2008; Norambuena et al. 2009).

Still, as we have experienced for Gal-1, special precaution and profound understanding of the context is vital, as other galectins also present apparently controversial outcomes depending on the model. For instance, breast cancer immunocompetent preclinical models show that absence of Gal-3 in the host mouse in fact boosts tumor growth and bone marrow metastasis (Pereira et al. 2016).

\section{Future trends and directions}


In this chapter, we discuss the current knowledge about Gal-1 functions in the tumor microenvironment. These effects of Gal-1 driving fibroblast activation, angiogenesis, and tumor immune suppression are deeply entangled with one another and cannot be understood separately (Figure 2). In lung cancer, for instance, Gal-1 secreted from tumor cells is important for fibroblast activation and induction of tryptophan catabolism by AKT signaling pathway and TDO2 (tryptophan 2,3-dioxygenase) and kynurenine (Kyn) upregulation, which contribute to immune evasion by impairing DC differentiation and T-cell function (Hsu et al. 2016). In fact, fibroblast activation promotes the secretion of chemokines and cytokines that are responsible for aberrant blood vessel formation in tumors and for establishing an immunosuppressive milieu (Masamune et al. 2006; Tang et al. 2012, 2016). Furthermore, tumor immune evasion driven by Gal-1 is not only a direct effect of Gal-1 over immune cell types but also a consequence of a deficient blood vessel network. Indeed, in 2014, Croci and colleagues reported that anti-Gal-1 antibody administration in immunocompetent melanoma and lung preclinical mouse models results in increased intratumoral infiltrates and tumordraining lymph node cells, which is at least partially due to vessel normalization (Croci et al. 2014). Tumor cells induce expression of Gal-1 by EC, which then inhibits T-cell transendothelial migration (as discussed above) (He and Baum 2006a). Interestingly, tumor growth as well as angiogenesis are more severely impaired upon TDG treatment in immunocompetent mice as compared to immunodeficient animals (Ito et al. 2011), highlighting the strong link between Gal-1-mediated immune regulation and cancer cell proliferation and vessel formation.

The tumor microenvironment has over the years emerged as a key governor of tissue malignancy that drives tumor development and progression (Hanahan and Weinberg 
2011) and is often the cause of ineffective therapies. Thus, strategies targeting the tumor soil have gained the interest of both basic and clinical researchers in virtually all tumor types, with thousands of clinical trials being designed and performed (EBioMedicine 2018; Degroote et al. 2018; Cuoco et al. 2018; Zandberg and Ferris 2018; Roma-Rodrigues et al. 2019; van Mackelenbergh et al. 2019). Although clinical trials are still in their infancy, robust preclinical data suggest that galectins may represent interesting targets in this tumor compartment (Ingrassia et al. 2006; Thijssen et al. 2015; Méndez-Huergo et al. 2017; Wdowiak et al. 2018; Dings et al. 2018). Among them, Gal-1 emerges as a top candidate with high potential, as this protein is a pleiotropic molecule that remodels the tumor microenvironment as a whole-including fibroblast activation, angiogenesis, and immune evasion- to allow uncontrolled tumor progression. Accordingly, development of Gal-1 inhibitors has currently a strong interest in cancer therapy and has shown promising results in several preclinical models (Ito et al. 2012; Astorgues-Xerri et al. 2014a). Moreover, taking into account the critical role of Gal-1 in immune evasion through its direct interaction with cell membrane receptors of effector T-cells triggering cell apoptosis, the Gal-1CD7/CD43/CD45 axis could be considered as a new immune checkpoint (like Gal3/LAG-3 and Gal-9/TIM-3; (Melero et al. 2015)); therefore, Gal-1 inhibitors could enlarge the list of novel cancer immunotherapies.

However, several issues are crucial for successful and proper drug development, such as having a profound understanding of the particular tumor type and galectin repertoire, deciphering redundant versus specific roles of each member, the endogenous versus exogenous roles of the protein, drug specificity, and so on. Classical in vivo models trying to study targets at the tumor microenvironment have 
shown limited translational success (Sharpless and Depinho 2006; Richmond and Su 2008). More recently, patient-derived cancer models, including organoids and patientderived xenografts (PDXs), have emerged in cancer preclinical studies, but they still lack the autochthonous tumor microenvironment (Weeber et al. 2017; Williams 2018). With the advent of immunotherapy, many groups have joined efforts to develop more suitable and more sophisticated models to allow the tumor as a whole to be investigated, such as using humanized mice (De La Rochere et al. 2018) and ex vivo systems that retain the whole native tumor microenvironment, such as 3D microfluidic cultures, tumor tissue explants, "tumor-on-a-chip", and multicellular tumor spheroids (Jenkins et al. 2018; Roma-Rodrigues et al. 2019). Further experiments in systems with better recapitulation of the tumor's surrounding will for sure be necessary for completing preclinical steps before moving Gal-1 therapy into the clinics.

In addition to the emerging attention on Gal-1 inhibitors as a novel cancer therapy, Gal-1 also offers other translational applications. For example, increasing data have unveiled the potential use of detecting Gal-1 levels for cancer diagnosis (Thijssen et al. 2015), as Gal-1 can be detected in biological fluids and, for many of the tumors expressing Gal-1, in the stroma (Table 1). Further, increased levels of the protein have been detected in plasma or serum from patients with cancer of thyroid (Saussez et al. 2008), colorectal (Watanabe et al. 2011), pancreatic cancer (Martinez-Bosch et al. 2018a), Hodgkin lymphoma (Ouyang et al. 2013), glioma (Verschuere et al. 2013), or OSCC (Aggarwal et al. 2015). Moreover, in the era of personalized medicine, Gal-1 may also work for selecting patients who respond better to anti-angiogenic or immunotherapies, and it could represent a useful biomarker for therapy response. 
Further preclinical and clinical data will be necessary to answer whether reality meets expectations to all of us working in the galectin world.

\section{Table Legends}

Table 1. Data on Gal-1 expression in the tumor microenvironment. This table summarizes the articles in which Gal-1 has been described in the tumor stroma by immunohistochemistry, describing the amount of samples analyzed and the functions and clinical correlations observed.

Figure Legends

Figure 1. Galectin family in mammalians. Fifteen galectins have been described in mammals, 11 of which have also been found in humans (located in the central core of the diagram). Galectins are organized in three groups: proto-type galectins that display one CRD and function as monomers or dimers; tandem-repeat galectins that have two CRDs linked; and chimeric-type galectins formed by Gal-3 with a long amino-terminal domain that allows oligomerization.

Figure 2. Gal-1 functions in the tumor microenvironment. Information regarding the roles of Gal-1 in fibroblast activation, induction of angiogenesis, and tumor immune suppression is shown in this overview picture. Precise data and references are found in the main text.

\section{Acknowledgments}

This work was supported by grants from the Spanish Ministry of Economy and Competitiveness/ISCIII-FEDER (PI17/00199), the Carmen Delgado/ Miguel Pérez-Mateo 
AESPANC-ACANPAN 2016 grant, and the Generalitat de Catalunya (2017-SGR-225) to P.N. We are also grateful to A. Flotats for help in graphic design and V. Raker for English proofreading and editing.

\section{References}

Abroun S, Otsuyama K-I, Shamsasenjan K, et al (2008) Galectin-1 supports the survival of CD45RA(-) primary myeloma cells in vitro. Br J Haematol 142:754-65

Aggarwal S, Sharma SC, Das SN (2015) Galectin-1 and galectin-3: Plausible tumour markers for oral squamous cell carcinoma and suitable targets for screening high-risk population. Clin Chim Acta 442:13-21

Astorgues-Xerri L, Riveiro ME, Tijeras-Raballand A, et al (2014a) Unraveling galectin-1 as a novel therapeutic target for cancer. Cancer Treat Rev 40:307-319

Astorgues-Xerri L, Riveiro ME, Tijeras-Raballand A, et al (2014b) OTX008, a selective small-molecule inhibitor of galectin-1, downregulates cancer cell proliferation, invasion and tumour angiogenesis. Eur J Cancer 50:2463-77

Baatar D, Olkhanud PB, Wells V, et al (2009) Tregs utilize beta-galactoside-binding protein to transiently inhibit PI3K/p21ras activity of human CD8+ T cells to block their TCR-mediated ERK activity and proliferation. Brain Behav Immun 23:1028-37

Baker GJ, Chockley P, Zamler D, et al (2016) Natural killer cells require monocytic Gr$1(+) / C D 11 b(+)$ myeloid cells to eradicate orthotopically engrafted glioma cells. Oncoimmunology 5:e1163461

Bänfer S, Schneider D, Dewes J, et al (2018) Molecular mechanism to recruit galectin-3 into multivesicular bodies for polarized exosomal secretion. Proc Natl Acad Sci USA 115:E4396-E4405

Banh A, Zhang J, Cao H, et al (2011) Tumor galectin-1 mediates tumor growth and metastasis through regulation of T-cell apoptosis. Cancer Res 71:4423-4431

Barondes SH, Castronovo V, Cooper DN, et al (1994) Galectins: a family of animal betagalactoside-binding lectins. Cell 76:597-598

Barrionuevo P, Beigier-Bompadre M, llarregui JM, et al (2007) A novel function for galectin-1 at the crossroad of innate and adaptive immunity: galectin-1 regulates monocyte/macrophage physiology through a nonapoptotic ERK-dependent pathway. J Immunol 178:436-445

Baum LG, Pang M, Perillo NL, et al (1995a) Human thymic epithelial cells express an endogenous lectin, galectin-1, which binds to core 2 O-glycans on thymocytes and T 
lymphoblastoid cells. J Exp Med 181:877-887

Baum LG, Seilhamer JJ, Pang M, et al (1995b) Synthesis of an endogeneous lectin, galectin-1, by human endothelial cells is up-regulated by endothelial cell activation. Glycoconj J 12:63-68

Berberat PO, Friess $\mathrm{H}$, Wang $\mathrm{L}$, et al (2001) Comparative analysis of galectins in primary tumors and tumor metastasis in human pancreatic cancer. J Histochem Cytochem 49:539-549

Berger BJ, Müller TS, Buschmann IR, et al (2003) High levels of the molecular chaperone Mdg1/ERdj4 reflect the activation state of endothelial cells. Exp Cell Res 290:82-92

Blaser C, Kaufmann M, Muller C, et al (1998) Beta-galactoside-binding protein secreted by activated $\mathrm{T}$ cells inhibits antigen-induced proliferation of $\mathrm{T}$ cells. Eur $\mathrm{J}$ Immunol 28:2311-2319

Blois SM, Ilarregui JM, Tometten $M$, et al (2007) A pivotal role for galectin-1 in fetomaternal tolerance. Nat Med 13:1450-1457

Bousseau S, Marchand M, Soleti R, et al (2019) Phostine 3.1a as a pharmacological compound with antiangiogenic properties against diseases with excess vascularization. FASEB J 33:5864-5875

Büchel G, Schulte JH, Harrison L, et al (2016) Immune response modulation by Galectin-1 in a transgenic model of neuroblastoma. Oncoimmunology 5:e1131378

Camby I, Le Mercier M, Lefranc F, Kiss R (2006) Galectin-1: a small protein with major functions. Glycobiology 16:137R-157R

Cedeno-Laurent F, Opperman M, Barthel SR, et al (2012a) Galectin-1 triggers an immunoregulatory signature in Th cells functionally defined by IL-10 expression. J Immunol 188:3127-37

Cedeno-Laurent F, Opperman MJ, Barthel SR, et al (2012b) Metabolic inhibition of galectin-1-binding carbohydrates accentuates antitumor immunity. J Invest Dermatol 132:410-20

Cedeno-Laurent F, Watanabe R, Teague JE, et al (2012c) Galectin-1 inhibits the viability, proliferation, and Th1 cytokine production of nonmalignant T cells in patients with leukemic cutaneous T-cell lymphoma. Blood 119:3534-3538

Cerliani JP, Blidner AG, Toscano MA, et al (2017) Translating the "Sugar Code" into Immune and Vascular Signaling Programs. Trends Biochem Sci 42:255-273

Chen Q, Han B, Meng X, et al (2019) Immunogenomic analysis reveals LGALS1 contributes to the immune heterogeneity and immunosuppression in glioma. Int $\mathrm{J}$ Cancer 145:517-530

Chen R, Pan S, Ottenhof NA, et al (2012) Stromal galectin-1 expression is associated with long-term survival in resectable pancreatic ductal adenocarcinoma. Cancer Biol 
Ther 13:899-907

Chong Y, Tang D, Xiong Q, et al (2016) Galectin-1 from cancer-associated fibroblasts induces epithelial-mesenchymal transition through $\beta 1$ integrin-mediated upregulation of Gli1 in gastric cancer. J Exp Clin Cancer Res 35:175

Chung CD, Patel VP, Moran M, et al (2000) Galectin-1 induces partial TCR zeta-chain phosphorylation and antagonizes processive TCR signal transduction. J Immunol 165:3722-9

Clausse N, van den Brûle F, Waltregny D, et al (1999) Galectin-1 expression in prostate tumor-associated capillary endothelial cells is increased by prostate carcinoma cells and modulates heterotypic cell-cell adhesion. Angiogenesis 3:317-325

Cooper D, Norling L V, Perretti M (2008) Novel insights into the inhibitory effects of Galectin-1 on neutrophil recruitment under flow. J Leukoc Biol 83:1459-1466

Correa SG, Sotomayor CE, Aoki MP, et al (2003) Opposite effects of galectin-1 on alternative metabolic pathways of L-arginine in resident, inflammatory, and activated macrophages. Glycobiology 13:119-128

Croci DO, Cerliani JP, Dalotto-Moreno T, et al (2014) Glycosylation-dependent lectinreceptor interactions preserve angiogenesis in anti-VEGF refractory tumors. Cell 156:744-58

Croci DO, Morande PE, Dergan-Dylon S, et al (2013) Nurse-like cells control the activity of chronic lymphocytic leukemia B cells via galectin-1. Leukemia 27:1413-1416

Croci DO, Salatino M, Rubinstein N, et al (2012) Disrupting galectin-1 interactions with $\mathrm{N}$-glycans suppresses hypoxia-driven angiogenesis and tumorigenesis in Kaposi's sarcoma. J Exp Med 209:1985-2000

Cummings RD, Liu F-T, Vasta GR (2015) Galectins. In: Varki A, Cummings RD, Esko JD et al. Essentials of Glycobiology. 3rd ed. Cold Spring Harbor (NY): Cold Spring Harbor Laboratory Press:2015-2017

Cuoco JA, Benko MJ, Busch CM, et al (2018) Vaccine-Based Immunotherapeutics for the Treatment of Glioblastoma: Advances, Challenges, and Future Perspectives. World Neurosurg 120:302-315

D'Haene N, Maris C, Sandras F, et al (2005) The differential expression of Galectin-1 and Galectin-3 in normal lymphoid tissue and non-Hodgkin's and Hodgkin's lymphomas. Int J Immunopathol Pharmacol 18:431-43

D'Haene N, Sauvage S, Maris C, et al (2013) VEGFR1 and VEGFR2 Involvement in Extracellular Galectin-1- and Galectin-3-Induced Angiogenesis. PLoS One 8:e67029

Dalotto-Moreno T, Croci DO, Cerliani JP, et al (2013) Targeting galectin-1 overcomes breast cancer-associated immunosuppression and prevents metastatic disease. Cancer Res 73:1107-1117

de la Fuente H, Cruz-Adalia A, Martinez del Hoyo G, et al (2014) The Leukocyte 
Activation Receptor CD69 Controls T Cell Differentiation through Its Interaction with Galectin-1. Mol Cell Biol 34:2479-2487

De La Rochere P, Guil-Luna S, Decaudin D, et al (2018) Humanized Mice for the Study of Immuno-Oncology. Trends Immunol 39:748-763

Degroote H, Van Dierendonck A, Geerts A, et al (2018) Preclinical and Clinical Therapeutic Strategies Affecting Tumor-Associated Macrophages in Hepatocellular Carcinoma. J Immunol Res 2018:1-9

Delgado VMC, Nugnes LG, Colombo LL, et al (2011) Modulation of endothelial cell migration and angiogenesis: a novel function for the \&quot;tandem-repeat\&quot; lectin galectin-8. FASEB J 25:242-54

Dings R, Miller M, Griffin R, Mayo K (2018) Galectins as Molecular Targets for Therapeutic Intervention. Int J Mol Sci 19:905

EBioMedicine (2018) The Tumor Microenvironment: A Druggable Target for Metastatic Disease? EBioMedicine 31:1-2

Etulain J, Negrotto S, Tribulatti MV, et al (2014) Control of angiogenesis by galectins involves the release of platelet-derived proangiogenic factors. PLoS One 9:e96402

Filer A, Bik M, Parsonage GN, et al (2009) Galectin 3 induces a distinctive pattern of cytokine and chemokine production in rheumatoid synovial fibroblasts via selective signaling pathways. Arthritis Rheum 60:1604-14

Frigeri LG, Robertson MW, Liu FT (1990) Expression of biologically active recombinant rat IgE-binding protein in Escherichia coli. J Biol Chem 265:20763-9

Fukumori T, Takenaka Y, Yoshii T, et al (2003) CD29 and CD7 mediate galectin-3induced type II T-cell apoptosis. Cancer Res 63:8302-11

Fulcher JA, Chang MH, Wang S, et al (2009) Galectin-1 Co-clusters CD43/CD45 on Dendritic Cells and Induces Cell Activation and Migration through Syk and Protein Kinase C Signaling. J Biol Chem 284:26860-26870

Fulcher JA, Hashimi ST, Levroney EL, et al (2006) Galectin-1-matured human monocytederived dendritic cells have enhanced migration through extracellular matrix. J Immunol 177:216-26

Funasaka T, Raz A, Nangia-Makker P (2014) Galectin-3 in angiogenesis and metastasis. Glycobiology 24:886-91

Gabius HJ, Brehler R, Schauer A, Cramer F (1986) Localization of endogenous lectins in normal human breast, benign breast lesions and mammary carcinomas. Virchows Arch B Cell Pathol Incl Mol Pathol 52:107-115

Garín MI, Chu C-C, Golshayan D, et al (2007) Galectin-1: a key effector of regulation mediated by CD4+CD25+ T cells. Blood 109:2058-65

Garner OB, Baum LG (2008) Galectin-glycan lattices regulate cell-surface glycoprotein 
organization and signalling. Biochem Soc Trans 36:1472-1477

Goldring K, Jones GE, Thiagarajah R, Watt DJ (2002) The effect of galectin-1 on the differentiation of fibroblasts and myoblasts in vitro. J Cell Sci 115:355-66

Hanahan D, Weinberg RAA (2011) Hallmarks of cancer: the next generation. Cell 144:646-674

Haudek KC, Patterson RJ, Wang JL (2010) SR proteins and galectins: what's in a name? Glycobiology 20:1199-207

He J, Baum LG (2004) Presentation of galectin-1 by extracellular matrix triggers T cell death. J Biol Chem 279:4705-4712

He J, Baum LG (2006a) Galectin interactions with extracellular matrix and effects on cellular function. Methods Enzym 417:247-256

He J, Baum LG (2006b) Endothelial cell expression of galectin-1 induced by prostate cancer cells inhibits T-cell transendothelial migration. Lab Investig 86:578-590

He X-J, Tao H-Q, Hu Z-M, et al (2014) Expression of galectin-1 in carcinoma-associated fibroblasts promotes gastric cancer cell invasion through upregulation of integrin $\beta 1$. Cancer Sci 105:1402-10

Henderson NC, Mackinnon AC, Farnworth SL, et al (2006) Galectin-3 regulates myofibroblast activation and hepatic fibrosis. Proc Natl Acad Sci U S A 103:5060-5

Hernandez JD, Nguyen JT, He J, et al (2006) Galectin-1 binds different CD43 glycoforms to cluster CD43 and regulate T cell death. J Immunol 177:5328-5336

Heusschen R, Schulkens IA, van Beijnum J, et al (2014) Endothelial LGALS9 splice variant expression in endothelial cell biology and angiogenesis. Biochim Biophys Acta Mol Basis Dis 1842:284-292

Hirabayashi J, Kasai K (1991) Effect of amino acid substitution by sited-directed mutagenesis on the carbohydrate recognition and stability of human 14-kDa betagalactoside-binding lectin. J Biol Chem 266:23648-53

Hirabayashi J, Kasai K (1993) The family of metazoan metal-independent betagalactoside-binding lectins: structure, function and molecular evolution. Glycobiology 3:297-304

Hsieh SH, Ying NW, Wu MH, et al (2008) Galectin-1, a novel ligand of neuropilin-1, activates VEGFR-2 signaling and modulates the migration of vascular endothelial cells. Oncogene 27:3746-3753

Hsu Y-L, Hung J-Y, Chiang S-Y, et al (2016) Lung cancer-derived galectin-1 contributes to cancer associated fibroblast-mediated cancer progression and immune suppression through TDO2/kynurenine axis. Oncotarget 7:27584-98

Huang C-S, Tang S-J, Chung L-Y, et al (2014) Galectin-1 upregulates CXCR4 to promote tumor progression and poor outcome in kidney cancer. J Am Soc Nephrol 25:1486-95 
Hughes RC (1999) Secretion of the galectin family of mammalian carbohydrate-binding proteins. Biochim Biophys Acta 1473:172-185

Hughes RC (2001) Galectins as modulators of cell adhesion. Biochimie 83:667-676

Ilarregui JM, Croci DO, Bianco GA, et al (2009) Tolerogenic signals delivered by dendritic cells to $T$ cells through a galectin-1-driven immunoregulatory circuit involving interleukin 27 and interleukin 10. Nat Immunol 10:981-991

Ingrassia L, Camby I, Lefranc F, et al (2006) Anti-galectin compounds as potential anticancer drugs. Curr Med Chem 13:3513-3527

Iqbal AJ, Sampaio ALF, Maione F, et al (2011) Endogenous Galectin-1 and Acute Inflammation. Am J Pathol 178:1201-1209

Ito K, Scott SA, Cutler S, et al (2011) Thiodigalactoside inhibits murine cancers by concurrently blocking effects of galectin-1 on immune dysregulation, angiogenesis and protection against oxidative stress. Angiogenesis 14:293-307

Ito K, Stannard K, Gabutero E, et al (2012) Galectin-1 as a potent target for cancer therapy: role in the tumor microenvironment. Cancer Metastasis Rev 31:763-78

Jaworski FM, Gentilini LD, Gueron G, et al (2017) In VivoHemin Conditioning Targets the Vascular and Immunologic Compartments and Restrains Prostate Tumor Development. Clin Cancer Res 23:5135-5148

Jenkins RW, Aref AR, Lizotte PH, et al (2018) Ex Vivo Profiling of PD-1 Blockade Using Organotypic Tumor Spheroids. Cancer Discov 8:196-215

Jeschke U, Karsten U, Wiest I, et al (2006) Binding of galectin-1 (gal-1) to the ThomsenFriedenreich (TF) antigen on trophoblast cells and inhibition of proliferation of trophoblast tumor cells in vitro by gal-1 or an anti-TF antibody. Histochem Cell Biol 126:437-44

Jiang Z-J, Shen Q-H, Chen H-Y, et al (2019) Galectin-1 gene silencing inhibits the activation and proliferation but induces the apoptosis of hepatic stellate cells from mice with liver fibrosis. Int J Mol Med 43:103-116

Jin Lim M, Ahn J, Youn Yi J, et al (2014) Induction of galectin-1 by TGF- $\beta 1$ accelerates fibrosis through enhancing nuclear retention of Smad2. Exp Cell Res 326:125-135

Johannes L, Jacob R, Leffler H (2018) Galectins at a glance. J Cell Sci 131

Jung E-JJ, Moon H-GG, Cho Bl, et al (2007) Galectin-1 expression in cancer-associated stromal cells correlates tumor invasiveness and tumor progression in breast cancer. Int J Cancer 120:2331-2338

Juszczynski P, Ouyang J, Monti S, et al (2007) The AP1-dependent secretion of galectin1 by Reed Sternberg cells fosters immune privilege in classical Hodgkin lymphoma. Proc Natl Acad Sci USA 104:13134-13139

Kim H-J, Jeon H-K, Cho YJ, et al (2012) High galectin-1 expression correlates with poor 
prognosis and is involved in epithelial ovarian cancer proliferation and invasion. Eur J Cancer 48:1914-1921

Kohrenhagen N, Volker HU, Kapp M, et al (2006) Increased expression of galectin-1 during the progression of cervical neoplasia. Int J Gynecol Cancer 16:2018-2022

Koonce NA, Griffin RJ, Dings RPM (2017) Galectin-1 Inhibitor OTX008 Induces Tumor Vessel Normalization and Tumor Growth Inhibition in Human Head and Neck Squamous Cell Carcinoma Models. Int J Mol Sci 18:2671

Kouo T, Huang L, Pucsek AB, et al (2015) Galectin-3 Shapes Antitumor Immune Responses by Suppressing CD8+ T Cells via LAG-3 and Inhibiting Expansion of Plasmacytoid Dendritic Cells. Cancer Immunol Res 3:412-23

Kuo P-L, Huang M-S, Cheng D-E, et al (2012) Lung cancer-derived galectin-1 enhances tumorigenic potentiation of tumor-associated dendritic cells by expressing heparinbinding EGF-like growth factor. J Biol Chem 287:9753-64

La M, Cao T V, Cerchiaro G, et al (2003) A novel biological activity for galectin-1: inhibition of leukocyte-endothelial cell interactions in experimental inflammation. Am J Pathol 163:1505-15

Laderach DJ, Gentilini LD, Giribaldi L, et al (2013) A unique galectin signature in human prostate cancer progression suggests galectin-1 as a key target for treatment of advanced disease. Cancer Res 73:86-96

Le Mercier M, Fortin S, Mathieu V, et al (2009) Galectin 1 proangiogenic and promigratory effects in the Hs683 oligodendroglioma model are partly mediated through the control of BEX2 expression. Neoplasia 11:485-496

Le Mercier M, Mathieu V, Haibe-Kains B, et al (2008) Knocking down galectin 1 in human hs683 glioblastoma cells impairs both angiogenesis and endoplasmic reticulum stress responses. J Neuropathol Exp Neurol 67:456-469

Le Q-T, Shi G, Cao H, et al (2005) Galectin-1: a link between tumor hypoxia and tumor immune privilege. J Clin Oncol 23:8932-41

Leffler H, Masiarz FR, Barondes SH (1989) Soluble lactose-binding vertebrate lectins: a growing family. Biochemistry 28:9222-9

Lehr JE, Pienta KJ (1998) Preferential adhesion of prostate cancer cells to a human bone marrow endothelial cell line. J Natl Cancer Inst 90:118-23

Li L, Li J, Gao J (2014) Functions of galectin-3 and its role in fibrotic diseases. J Pharmacol Exp Ther 351:336-43

Lin Y-T, Chen J-S, Wu M-H, et al (2015) Galectin-1 accelerates wound healing by regulating the neuropilin-1/Smad3/NOX4 pathway and ROS production in myofibroblasts. J Invest Dermatol 135:258-268

Logullo AF, Lopes ABG, Nonogaki S, et al (2007) C-erbB-2 expression is a better predictor for survival than galectin-3 or p53 in early-stage breast cancer. Oncol Rep 
Lopez-Lucendo MF, Solis D, Andre S, et al (2004) Growth-regulatory human galectin-1: crystallographic characterisation of the structural changes induced by single-site mutations and their impact on the thermodynamics of ligand binding. J Mol Biol 343:957-970

Lotan R, Belloni PN, Tressler RJ, et al (1994) Expression of galectins on microvessel endothelial cells and their involvement in tumour cell adhesion. Glycoconj J 11:462468

Lykken JM, Horikawa M, Minard-Colin V, et al (2016) Galectin-1 drives lymphoma CD20 immunotherapy resistance: validation of a preclinical system to identify resistance mechanisms. Blood 127:1886-95

Machado CML, Andrade LNS, Teixeira VR, et al (2014) Galectin-3 disruption impaired tumoral angiogenesis by reducing VEGF secretion from TGF 6 1-induced macrophages.

Cancer Med 3:201-214

Maeda N, Kawada N, Seki S, et al (2003) Stimulation of proliferation of rat hepatic stellate cells by galectin-1 and galectin-3 through different intracellular signaling pathways. J Biol Chem 278:18938-18944

Manzi M, Bacigalupo ML, Carabias P, et al (2016) Galectin-1 Controls the Proliferation and Migration of Liver Sinusoidal Endothelial Cells and Their Interaction With Hepatocarcinoma Cells. J Cell Physiol 231:1522-1533

Markowska Al, Jefferies KC, Panjwani N (2011) Galectin-3 protein modulates cell surface expression and activation of vascular endothelial growth factor receptor 2 in human endothelial cells. J Biol Chem 286:29913-21

Markowska Al, Liu F-T, Panjwani N (2010) Galectin-3 is an important mediator of VEGFand bFGF-mediated angiogenic response. J Exp Med 207:1981-1993

Martinez-Bosch N, Barranco LE, Orozco CA, et al (2018a) Increased plasma levels of galectin-1 in pancreatic cancer: Potential use as biomarker. Oncotarget 9:32984-96

Martínez-Bosch N, Fernandez-Barrena MG, Moreno M, et al (2014) Galectin-1 drives pancreatic carcinogenesis through stroma remodeling and Hedgehog signaling activation. Cancer Res 74:3512-3524

Martinez-Bosch N, Vinaixa J, Navarro P (2018b) Immune Evasion in Pancreatic Cancer: from Mechanisms to Therapy. Cancers (Basel):10

Masamune A, Satoh M, Hirabayashi J, et al (2006) Galectin-1 induces chemokine production and proliferation in pancreatic stellate cells. Am J Physiol Gastrointest Liver Physiol 290:G729-G736

Mathieu V, de Lassalle EM, Toelen J, et al (2012) Galectin-1 in Melanoma Biology and Related Neo-Angiogenesis Processes. J Invest Dermatol 132:2245-2254

Melero I, Berman DM, Aznar MA, et al (2015) Evolving synergistic combinations of 
targeted immunotherapies to combat cancer. Nat Rev Cancer 15:457-472

Méndez-Huergo SP, Blidner AG, Rabinovich GA (2017) Galectins: emerging regulatory checkpoints linking tumor immunity and angiogenesis. Curr Opin Immunol 45:8-15

Nangia-Makker P, Conklin J, Hogan V, Raz A (2002a) Carbohydrate-binding proteins in cancer, and their ligands as therapeutic agents. Trends MolMed 8:187-192

Nangia-Makker P, Hogan V, Honjo Y, et al (2002b) Inhibition of Human Cancer Cell Growth and Metastasis in Nude Mice by Oral Intake of Modified Citrus Pectin. JNCI J Natl Cancer Inst 94:1854-1862

Nangia-Makker P, Honjo Y, Sarvis R, et al (2000) Galectin-3 induces endothelial cell morphogenesis and angiogenesis. Am J Pathol 156:899-909

Norambuena A, Metz C, Vicuña L, et al (2009) Galectin-8 induces apoptosis in Jurkat T cells by phosphatidic acid-mediated ERK1/2 activation supported by protein kinase $A$ down-regulation. J Biol Chem 284:12670-9

Norling L V, Sampaio AL, Cooper D, Perretti M (2008) Inhibitory control of endothelial galectin-1 on in vitro and in vivo lymphocyte trafficking. FASEB J 22:682-690

Orozco CA, Martinez-Bosch N, Guerrero PE, et al (2018) Targeting galectin-1 inhibits pancreatic cancer progression by modulating tumor-stroma crosstalk. Proc Natl Acad Sci USA 115:E3769-E3778

Ouyang J, Plutschow A, von Strandmann EP, et al (2013) Galectin-1 serum levels reflect tumor burden and adverse clinical features in classical Hodgkin lymphoma. Blood 121:3431-3433

Ozawa K, Tsukamoto Y, Hori O, et al (2001) Regulation of tumor angiogenesis by oxygen-regulated protein 150, an inducible endoplasmic reticulum chaperone. Cancer Res 61:4206-13

Pace KE, Lee C, Stewart PL, Baum LG (1999) Restricted receptor segregation into membrane microdomains occurs on human $\mathrm{T}$ cells during apoptosis induced by galectin-1. J Immunol 163:3801-3811

Paclik D, Berndt U, Guzy C, et al (2008) Galectin-2 induces apoptosis of lamina propria $\mathrm{T}$ lymphocytes and ameliorates acute and chronic experimental colitis in mice. J Mol Med (Berl) 86:1395-406

Pan S, Chen R, Reimel BA, et al (2009) Quantitative proteomics investigation of pancreatic intraepithelial neoplasia. Electrophoresis 30:1132-1144

Peng W, Wang HY, Miyahara Y, et al (2008) Tumor-Associated Galectin-3 Modulates the Function of Tumor-Reactive T Cells. Cancer Res 68:7228-7236

Pereira JX, Azeredo MCB, Martins FS, et al (2016) The deficiency of galectin-3 in stromal cells leads to enhanced tumor growth and bone marrow metastasis. BMC Cancer 16:636 
Pérez C V, Gómez LG, Gualdoni GS, et al (2015) Dual roles of endogenous and exogenous galectin-1 in the control of testicular immunopathology. Sci Rep 5:12259

Perillo NL, Pace KE, Seilhamer JJ, Baum LG (1995) Apoptosis of T cells mediated by galectin-1. Nature 378:736-739

Pinho SS, Reis CA (2015) Glycosylation in cancer: mechanisms and clinical implications. Nat Rev Cancer 15:540-55

Poncini C V., Ilarregui JM, Batalla El, et al (2015) Trypanosoma cruzi Infection Imparts a Regulatory Program in Dendritic Cells and $T$ Cells via Galectin-1-Dependent Mechanisms. J Immunol 195:3311-3324

Popa SJ, Stewart SE, Moreau K (2018) Unconventional secretion of annexins and galectins. Semin Cell Dev Biol 83:42-50

Rabinovich G a, Iglesias MM, Modesti NM, et al (1998) Activated rat macrophages produce a galectin-1-like protein that induces apoptosis of $\mathrm{T}$ cells: biochemical and functional characterization. JImmunol 160:4831-4840

Rabinovich GA, Ariel A, Hershkoviz R, et al (1999a) Specific inhibition of T-cell adhesion to extracellular matrix and proinflammatory cytokine secretion by human recombinant galectin-1. Immunology 97:100-106

Rabinovich GA, Conejo-García JR (2016) Shaping the Immune Landscape in Cancer by Galectin-Driven Regulatory Pathways. J Mol Biol 428:3266-3281

Rabinovich GA, Daly G, Dreja H, et al (1999b) Recombinant galectin-1 and its genetic delivery suppress collagen-induced arthritis via T cell apoptosis. J Exp Med 190:385398

Rabinovich GA, Ramhorst RE, Rubinstein N, et al (2002) Induction of allogenic T-cell hyporesponsiveness by galectin-1-mediated apoptotic and non-apoptotic mechanisms. Cell Death Differ 9:661-670

Rabinovich GA, Toscano MA (2009) Turning "sweet" on immunity: galectin-glycan interactions in immune tolerance and inflammation. Nat Rev Immunol 9:338-352

Rabinovich GA, Toscano MA, Jackson SS, Vasta GR (2007) Functions of cell surface galectin-glycoprotein lattices. Curr Opin Struct Biol 17:513-520

Raz A, Lotan R (1981) Lectin-like activities associated with human and murine neoplastic cells. Cancer Res 41:3642-7

Raz A, Lotan R (1987) Endogenous galactoside-binding lectins: a new class of functional tumor cell surface molecules related to metastasis. Cancer Metastasis Rev 6:433-52

Renatus M, Engh RA, Stubbs MT, et al (1997) Lysine 156 promotes the anomalous proenzyme activity of tPA: X-ray crystal structure of single-chain human tPA. EMBO J 16:4797-4805

Richmond A, Su Y (2008) Mouse xenograft models vs GEM models for human cancer 
therapeutics. Dis Model Mech 1:78-82

Ridano ME, Subirada P V, Paz MC, et al (2017) Galectin-1 expression imprints a neurovascular phenotype in proliferative retinopathies and delineates responses to anti-VEGF. Oncotarget 8:32505-32522

Roma-Rodrigues C, Mendes R, Baptista P, Fernandes A (2019) Targeting Tumor Microenvironment for Cancer Therapy. Int J Mol Sci 20:840

Rostoker R, Yaseen H, Schif-Zuck S, et al (2013) Galectin-1 induces 12/15-lipoxygenase expression in murine macrophages and favors their conversion toward a pro-resolving phenotype. Prostaglandins Other Lipid Mediat 107:85-94

Rubinstein N, Alvarez M, Zwirner NW, et al (2004) Targeted inhibition of galectin-1 gene expression in tumor cells results in heightened $\mathrm{T}$ cell-mediated rejection; $\mathrm{A}$ potential mechanism of tumor-immune privilege. Cancer Cell 5:241-251

Rutkowski MRR, Stephen TLL, Svoronos N, et al (2015) Microbially driven TLR5dependent signaling governs distal malignant progression through tumor-promoting inflammation. Cancer Cell 27:27-40

Sanjuan X, Fernandez PL, Castells A, et al (1997) Differential expression of galectin 3 and galectin 1 in colorectal cancer progression. Gastroenterology 113:1906-1915

Santos SN dos, Sheldon H, Pereira JX, et al (2017) Galectin-3 acts as an angiogenic switch to induce tumor angiogenesis via Jagged-1/Notch activation. Oncotarget 8:49484-49501

Santucci L, Fiorucci S, Rubinstein N, et al (2003) Galectin-1 suppresses experimental colitis in mice. Gastroenterology 124:1381-94

Saussez S, Decaestecker C, Cludts S, et al (2009) Adhesion/growth-regulatory tissue lectin galectin-1 in relation to angiogenesis/lymphocyte infiltration and prognostic relevance of stromal up-regulation in laryngeal carcinomas. Anticancer Res 29:59-65

Saussez S, Glinoer D, Chantrain G, et al (2008) Serum galectin-1 and galectin-3 levels in benign and malignant nodular thyroid disease. Thyroid 18:705-12

Schulz H, Schmoeckel E, Kuhn C, et al (2017) Galectins-1, -3, and -7 Are Prognostic Markers for Survival of Ovarian Cancer Patients. Int J Mol Sci 18:1230

Sharpless NE, Depinho RA (2006) The mighty mouse: genetically engineered mouse models in cancer drug development. Nat Rev Drug Discov 5:741-54

Shekhar MPV, Nangia-Makker P, Tait L, et al (2004) Alterations in Galectin-3 Expression and Distribution Correlate with Breast Cancer Progression. Am J Pathol 165:1931-1941

Shen J, Person MD, Zhu J, et al (2004) Protein expression profiles in pancreatic adenocarcinoma compared with normal pancreatic tissue and tissue affected by pancreatitis as detected by two-dimensional gel electrophoresis and mass spectrometry. Cancer Res 64:9018-9026 
Soker S, Takashima S, Miao HQ, et al (1998) Neuropilin-1 is expressed by endothelial and tumor cells as an isoform-specific receptor for vascular endothelial growth factor. Cell 92:735-45

Soldati R, Berger E, Zenclussen AC, et al (2012) Neuroblastoma triggers an immunoevasive program involving galectin-1-dependent modulation of $\mathrm{T}$ cell and dendritic cell compartments. Int J cancer 131:1131-41

Spano D, Russo R, Di V M, et al (2010) Galectin-1 and its involvement in hepatocellular carcinoma aggressiveness. Mol Med 16:102-115

Stannard KA, Collins PM, Ito K, et al (2010) Galectin inhibitory disaccharides promote tumour immunity in a breast cancer model. Cancer Lett 299:95-110

Stillman BN, Hsu DK, Pang M, et al (2006) Galectin-3 and galectin-1 bind distinct cell surface glycoprotein receptors to induce T cell death. J Immunol 176:778-789

Storti P, Marchica V, Airoldi I, et al (2016) Galectin-1 suppression delineates a new strategy to inhibit myeloma-induced angiogenesis and tumoral growth in vivo. Leukemia 30:2351-2363

Stowell SR, Karmakar S, Arthur CM, et al (2009) Galectin-1 induces reversible phosphatidylserine exposure at the plasma membrane. Mol Biol Cell 20:1408-18

Sundblad V, Mathieu V, Kiss R, Rabinovich GA (2013) Galectins: Key Players in the Tumor Microenvironment. Cancer Immunother 537-563

Tang D, Gao J, Wang S, et al (2016) Cancer-associated fibroblasts promote angiogenesis in gastric cancer through galectin-1 expression. Tumor Biol 37:1889-1899

Tang D, Gao J, Wang S, et al (2015) Apoptosis and anergy of T cell induced by pancreatic stellate cells-derived galectin-1 in pancreatic cancer. Tumor Biol 36:56175626

Tang D, Wu Q, Zhang J, et al (2018) Galectin-1 expression in activated pancreatic satellite cells promotes fibrosis in chronic pancreatitis/pancreatic cancer via the TGF$\beta 1 /$ Smad pathway. Oncol Rep 39:1347-1355

Tang D, Yuan Z, Xue X, et al (2012) High expression of Galectin-1 in pancreatic stellate cells plays a role in the development and maintenance of an immunosuppressive microenvironment in pancreatic cancer. Int J Cancer 130:2337-2348

Tang D, Zhang J, Yuan Z, et al (2014) Pancreatic satellite cells derived galectin-1 increase the progression and less survival of pancreatic ductal adenocarcinoma. PLoS One 9:e90476

Teichberg VI, Silman I, Beitsch DD, Resheff G (1975) A beta-D-galactoside binding protein from electric organ tissue of Electrophorus electricus. Proc Natl Acad Sci USA 72:1383-7

Tesone AJ, Rutkowski MR, Brencicova E, et al (2016) Satb1 Overexpression Drives Tumor-Promoting Activities in Cancer-Associated Dendritic Cells. Cell Rep 14:1774- 
Thiemann S, Baum LG (2016) Galectins and Immune Responses-Just How Do They Do Those Things They Do? Annu Rev Immunol 34:243-264

Thiemann S, Man JH, Chang MH, et al (2015) Galectin-1 regulates tissue exit of specific dendritic cell populations. J Biol Chem 290:22662-77

Thijssen VL, Barkan B, Shoji H, et al (2010) Tumor cells secrete galectin-1 to enhance endothelial cell activity. Cancer Res 70:6216-24

Thijssen VL, Heusschen R, Caers J, Griffioen AW (2015) Galectin expression in cancer diagnosis and prognosis: A systematic review. Biochim Biophys Acta 1855:235-47

Thijssen VL, Hulsmans S, Griffioen AW (2008) The galectin profile of the endothelium: altered expression and localization in activated and tumor endothelial cells. Am J Pathol 172:545-553

Thijssen VL, Postel R, Brandwijk RJ, et al (2006) Galectin-1 is essential in tumor angiogenesis and is a target for antiangiogenesis therapy. Proc Natl Acad Sci USA 103:15975-15980

Thijssen VLL, Poirier F, Baum LG, Griffioen AW (2007) Galectins in the tumor endothelium: opportunities for combined cancer therapy. Blood 110:2819-2827

Toscano MA, Bianco GA, Ilarregui JM, et al (2007) Differential glycosylation of TH1, TH2 and TH-17 effector cells selectively regulates susceptibility to cell death. Nat Immunol $8: 825-834$

Toscano MA, Commodaro AG, llarregui JM, et al (2006) Galectin-1 Suppresses Autoimmune Retinal Disease by Promoting Concomitant Th2- and T RegulatoryMediated Anti-Inflammatory Responses. J Immunol 176:6323-6332

Tribulatti MV, Mucci J, Cattaneo V, et al (2007) Galectin-8 induces apoptosis in the CD4(high)CD8(high) thymocyte subpopulation. Glycobiology 17:1404-12

Troncoso MF, Ferragut F, Bacigalupo ML, et al (2014) Galectin-8: A matricellular lectin with key roles in angiogenesis. Glycobiology 24:907-914

Tsai C-M, Wu H-Y, Su T-H, et al (2014) Phosphoproteomic analyses reveal that galectin1 augments the dynamics of B-cell receptor signaling. J Proteomics 103:241-53

Tsuboi S, Sutoh M, Hatakeyama S, et al (2011) A novel strategy for evasion of NK cell immunity by tumours expressing core2 O-glycans. EMBO J 30:3173-85

Valach J, Fik Z, Strnad H, et al (2012) Smooth muscle actin-expressing stromal fibroblasts in head and neck squamous cell carcinoma: increased expression of galectin-1 and induction of poor prognosis factors. Int J Cancer 131:2499-508

van den Brûle FA, Califice S, Garnier F, et al (2003) Galectin-1 accumulation in the ovary carcinoma peritumoral stroma is induced by ovary carcinoma cells and affects both cancer cell proliferation and adhesion to laminin-1 and fibronectin. Lab Invest 
van den Brûle FA, Buicu C, Baldet $M$, et al (1995) Galectin-1 modulates human melanoma cell adhesion to laminin. Biochem Biophys Res Commun 209:760-767

van den Brûle FA, Waltregny D, Castronovo V, et al (2001) Increased expression of galectin-1 in carcinoma-associated stroma predicts poor outcome in prostate carcinoma patients. JPathol 193:80-87

van Mackelenbergh MG, Stroes Cl, Spijker R, et al (2019) Clinical Trials Targeting the Stroma in Pancreatic Cancer: A Systematic Review and Meta-Analysis. Cancers (Basel) 11:588

Van Woensel M, Mathivet T, Wauthoz N, et al (2017) Sensitization of glioblastoma tumor micro-environment to chemo- and immunotherapy by Galectin-1 intranasal knock-down strategy. Sci Rep 7:1217

Varki A, Cummings RD, Esko JD, et al (2015) Essentials of Glycobiology. 3rd ed. Cold Spring Harbor (NY): Cold Spring Harbor Laboratory Press:2015-2017

Verschuere T, Toelen J, Maes W, et al (2014) Glioma-derived galectin-1 regulates innate and adaptive antitumor immunity. Int J Cancer 134:873-884

Verschuere T, Van Woensel M, Fieuws S, et al (2013) Altered galectin-1 serum levels in patients diagnosed with high-grade glioma. J Neurooncol 115:9-17

Wang W, Guo H, Geng J, et al (2014) Tumor-released Galectin-3, a soluble inhibitory ligand of human NKp30, plays an important role in tumor escape from NK cell attack. J Biol Chem 289:33311-9

Watanabe M, Takemasa I, Kaneko N, et al (2011) Clinical significance of circulating galectins as colorectal cancer markers. Oncol Rep 25:1217-26

Wdowiak K, Francuz T, Gallego-Colon E, et al (2018) Galectin Targeted Therapy in Oncology: Current Knowledge and Perspectives. Int J Mol Sci 19

Weeber F, Ooft SN, Dijkstra KK, Voest EE (2017) Tumor Organoids as a Pre-clinical Cancer Model for Drug Discovery. Cell Chem Biol 24:1092-1100

Whitney PL, Powell JT, Sanford GL (1986) Oxidation and chemical modification of lung $\beta$-galactoside-specific lectin. Biochem J 238:683-689

Williams J (2018) Using PDX for Preclinical Cancer Drug Discovery: The Evolving Field. J Clin Med 7:41

$\mathrm{Wu} \mathrm{H}$, Chen P, Liao R, et al (2012) Overexpression of galectin-1 is associated with poor prognosis in human hepatocellular carcinoma following resection. J Gastroenterol Hepatol 27:1312-1319

$\mathrm{Wu} \mathrm{M}-\mathrm{H}$, Chen $\mathrm{Y}-\mathrm{L}$, Lee $\mathrm{K}-\mathrm{H}$, et al (2017a) Glycosylation-dependent galectin$1 /$ neuropilin-1 interactions promote liver fibrosis through activation of TGF- $\beta$ - and PDGF-like signals in hepatic stellate cells. Sci Rep 7:11006 
Wu M-H, Ying N-W, Hong T-M, et al (2014) Galectin-1 induces vascular permeability through the neuropilin-1/vascular endothelial growth factor receptor-1 complex. Angiogenesis 17:839-849

Wu MH, Hong HC, Hong TM, et al (2011) Targeting Galectin-1 in Carcinoma-Associated Fibroblasts Inhibits Oral Squamous Cell Carcinoma Metastasis by Downregulating MCP1/CCL2 Expression. Clin Cancer Res 17:1306-1316

Wu X, Li J, Connolly EM, et al (2017b) Combined Anti-VEGF and Anti-CTLA-4 Therapy Elicits Humoral Immunity to Galectin-1 Which Is Associated with Favorable Clinical Outcomes. Cancer Immunol Res 5:446-454

Xue X, Lu Z, Tang D, et al (2011) Galectin-1 secreted by activated stellate cells in pancreatic ductal adenocarcinoma stroma promotes proliferation and invasion of pancreatic cancer cells: an in vitro study on the microenvironment of pancreatic ductal adenocarcinoma. Pancreas 40:832-839

You Y, Tan J-X, Dai H-S, et al (2016) MiRNA-22 inhibits oncogene galectin-1 in hepatocellular carcinoma. Oncotarget 7:57099-57116

Zandberg DP, Ferris RL (2018) Window Studies in Squamous Cell Carcinoma of the Head and Neck: Values and Limits. Curr Treat Options Oncol 19:68

Zhao W, Ajani JA, Sushovan G, et al (2018) Galectin-3 Mediates Tumor Cell-Stroma Interactions by Activating Pancreatic Stellate Cells to Produce Cytokines via Integrin Signaling. Gastroenterology 154:1524-1537.e6

Zhao XY, Chen TT, Xia L, et al (2010) Hypoxia inducible factor-1 mediates expression of galectin-1: the potential role in migration/invasion of colorectal cancer cells. Carcinogenesis 31:1367-1375

Zhou G, Sprengers D, Boor PPC, et al (2017) Antibodies Against Immune Checkpoint Molecules Restore Functions of Tumor-Infiltrating $T$ Cells in Hepatocellular Carcinomas. Gastroenterology 153:1107-1119.e10

Zhu C, Anderson AC, Schubart A, et al (2005) The Tim-3 ligand galectin-9 negatively regulates T helper type 1 immunity. Nat Immunol 6:1245-1252

Zhu X, Wang K, Zhang K, et al (2016) Galectin-1 knockdown in carcinoma-associated fibroblasts inhibits migration and invasion of human MDA-MB-231 breast cancer cells by modulating MMP-9 expression. Acta Biochim Biophys Sin (Shanghai) 48:462-7

Zucchetti M, Bonezzi K, Frapolli R, et al (2013) Pharmacokinetics and antineoplastic activity of galectin-1-targeting OTX008 in combination with sunitinib. Cancer Chemother Pharmacol 72:879-87 
FIGURES

Figure 1

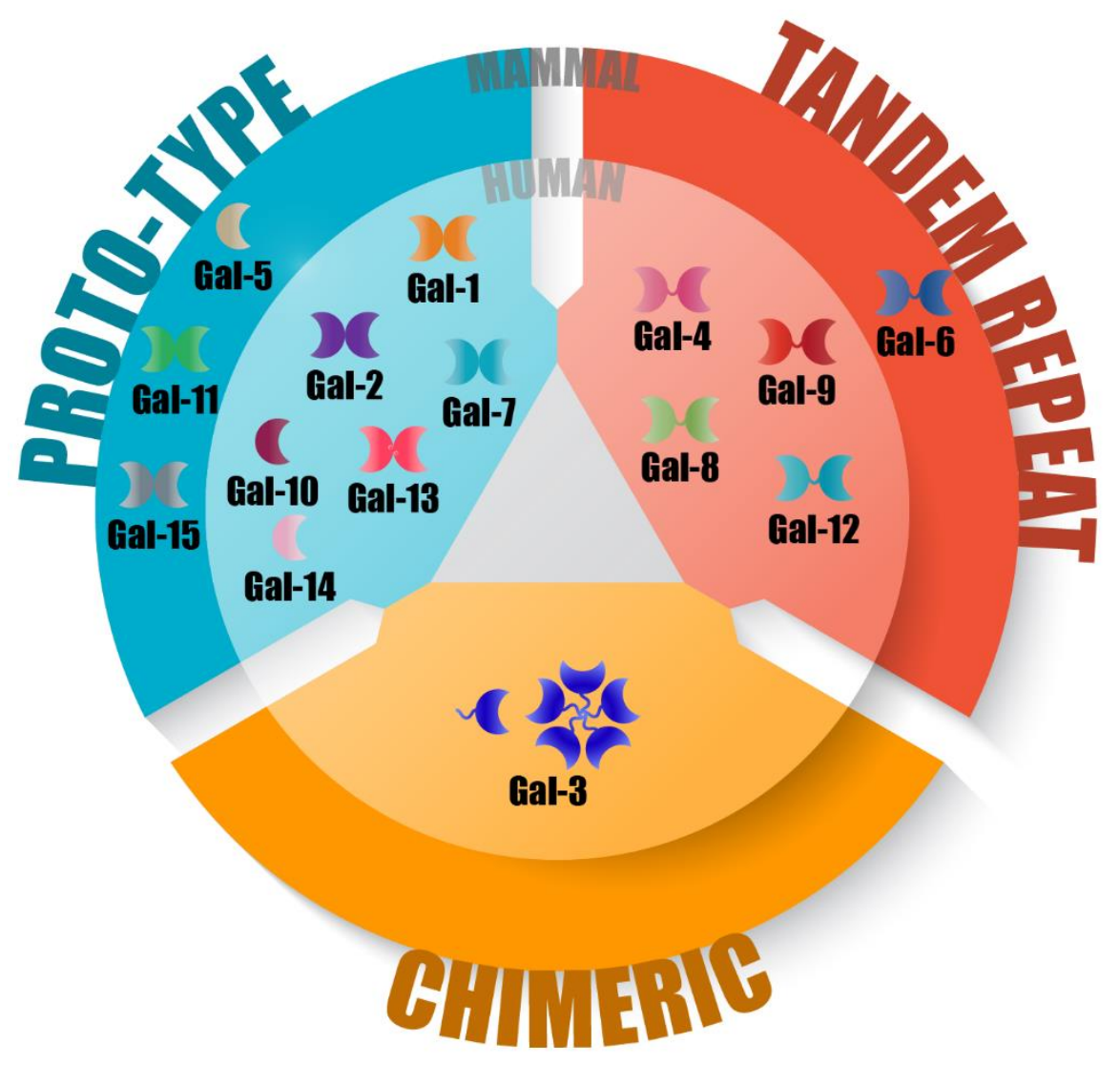


Figure 2

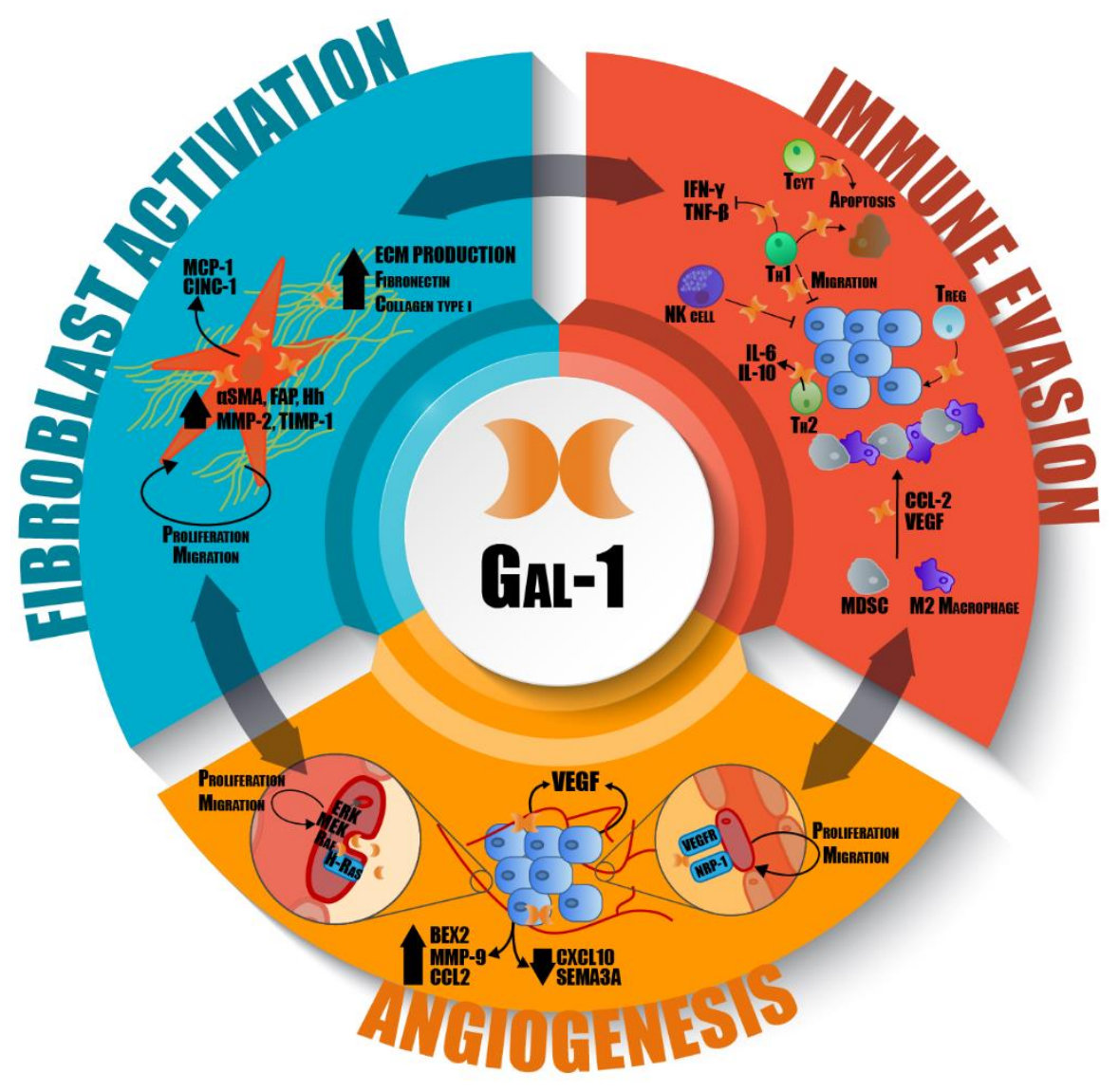

